\title{
The Asian Financial Crisis and international reserve accumulation: A robust control approach
}

\author{
Sang Seok Lee ${ }^{\mathrm{a}, *}$, Paul Luk ${ }^{\mathrm{b}}$ \\ a Department of Economics, Bilkent University, Ankara, 06800, Turkey \\ ${ }^{\mathrm{b}}$ Department of Economics, Hong Kong Baptist University, WLB 530, 34 Renfrew Road, Kowloon Tong, Kowloon, Hong Kong
}

\section{A R T I C L E I N F O}

\section{Article history:}

Received 21 September 2017

Revised 19 March 2018

Accepted 23 March 2018

Available online 29 March 2018

\section{JEL classification:}

D81

D83

F41

Keywords:

The Asian Financial Crisis

International reserves

Structural breaks

Model uncertainty

Robust control and learning

\begin{abstract}
A B S T R A C T
Standard macroeconomic models have difficulties accounting for the surge in international reserves of Asian countries in the aftermath of the Asian Financial Crisis of 1997. We propose precautionary demand for saving generated by model uncertainty as an important driver of this phenomenon. Using Korean data, we estimate a simple permanent income model augmented with model uncertainty, find a structural break at the point of the Asian Financial Crisis, and identify a rise in concern for model misspecification which is distinct from an increase in income volatility. The post-crisis concern for model misspecification implies a reasonable detection error probability. We also show that learning serves as an additional powerful amplification mechanism in our framework.
\end{abstract}

(c) 2018 Elsevier B.V. All rights reserved.

\section{Introduction}

The accumulation of international reserves in many emerging market countries took a dramatic turn in the aftermath of the Asian Financial Crisis of 1997. Fig. 1 plots the simple averages of international reserves to GDP ratios for several groups of countries from 1980 to 2013. From a number slightly above $10 \%$ in the mid 90s, international reserves to GDP ratio of the emerging market countries started trending upward following the crisis and nearly doubled by 2009. This pattern is particularly pronounced among Asian countries that were either directly affected by the crisis or close to its epicenter ("AFC + Russia" in the figure ${ }^{1}$ ). The literature has found the quantitative aspect of this surge puzzling as the reserve accumulation in these countries now far exceeds popular measures of reserve adequacy such as 3 to 6 months of imports or full coverage of short-term external debts known as Guidotti-Greenspan rule (Jeanne, 2007). Moreover, standard macroeconomic models have difficulties accounting for this magnitude without resorting to very high levels of risk aversion (Jeanne, 2007; Jeanne and Rancière, 2011).

In this paper, we show that model uncertainty helps us understand the international reserve accumulation by Asian countries in the aftermath of the Asian Financial Crisis. Under model uncertainty, economic agents are no longer endowed

\footnotetext{
* Corresponding author.

E-mail addresses: sang.lee@bilkent.edu.tr (S.S. Lee), paulskluk@hkbu.edu.hk (P. Luk).

${ }^{1}$ Russia is included in the group due to the close connection between its crisis (which occurred in August of 1998) and the Asian Financial Crisis. The figure is insensitive to the exclusion of China from the group.
} 


\section{Reserves to GDP Ratio (in \%)}

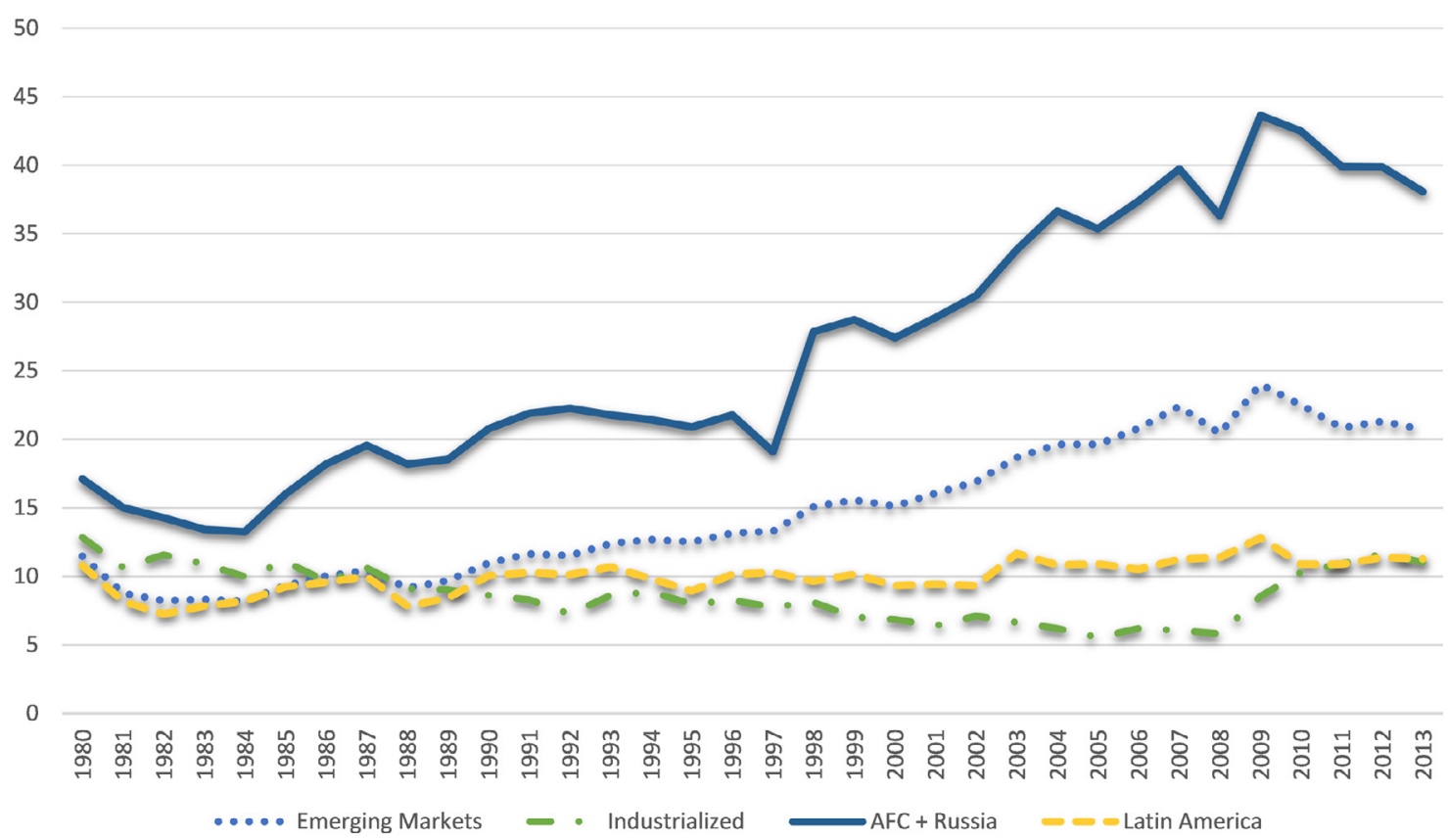

Fig. 1. International reserves to GDP ratio from 1994 to 2013 (in \%). Data source: World Bank World Development Indicators. Total international reserves consist of foreign exchange under the control of monetary authorities, monetary gold, special drawing rights, and IMF positions. The figure plots simple averages of countries under the same classification. Emerging Market and Industrialized countries classifications are based on Jeanne (2007). Emerging Markets: Argentina, Brazil, Bulgaria, Chile, China, Colombia, Cote d'Ivore, Dominican Republic, Ecuador, Egypt, El Salvador, Hungary, India, Indonesia, Korea, Malaysia, Mexico, Morocco, Nigeria, Pakistan, Panama, Peru, Philippines, Poland, Russia, Singapore, South Africa, Thailand, Tunisia, Turkey, Ukraine, Uruguay, and Venezuela. Industrialized: Australia, Austria, Belgium, Canada, Denmark, Finland, France, Germany, Greece, Iceland, Ireland, Italy, Japan, Luxembourg, Netherlands, New Zealand, Norway, Portugal, Spain, Sweden, Switzerland, United Kingdom, and United States. AFC + Russia: China, Indonesia, Korea, Malaysia, Philippines, Russia (included from 1993 onward), Singapore, and Thailand. Latin America: Argentina, Brazil, Chile, Colombia, Dominican Republic, Ecuador, El Salvador, Mexico, Panama, Uruguay, and Venezuela.

with a unique model of the economy. Instead, they entertain a set of possible models and make decisions which reflect this multiplicity. We employ robust control techniques (Hansen et al., 2010; Hansen and Sargent, 2008a; 2010; Hansen et al., 1999) to model economic agents who cope with model uncertainty by making decisions that serve them best under the worst case scenario.

We follow Jeanne and Rancière (2011) and model international reserves as an instrument of government's social planning problem. The social planner maximizes the representative household's utility by choosing consumption and saving, which is in the form of international reserves, subject to a stochastic income-generating process. Because we focus on the relationship between model uncertainty and the social planner's optimal reserve policy, private sector decisions related to the reserve accumulation are not explicitly modeled in the paper. However, their connection to the model features will be discussed. The interaction between model uncertainty and income volatility will be examined as well.

Our baseline model is a version of Hansen et al. (1999) permanent income model. The use of this model has three justifications. First, the model is well-understood so we can focus on the empirical analysis. Second, the model shares common features with other small open economy models and models of international reserves so our results are highly comparable to theirs. For instance, Luo et al. (2012) use a linear-quadratic permanent income model with robustness to study current account dynamics in a small open economy. Stylized models with exogenous income processes are used extensively in the international reserve accumulation literature (Bianchi et al., 2016; Jeanne, 2013; Jeanne and Rancière, 2011), and these models have yielded important insights. We follow this tradition. Third, although our model abstracts from institutional features (which vary across different crisis-affected economies), we will argue that our key mechanism is likely to survive in a more elaborate model.

We focus on the Korean crisis episode and the associated reserve accumulation given (a) the prominence of its crisis episode in the literature and (b) the availability and reliability of its macroeconomic and financial data. ${ }^{2}$ We estimate the model using quarterly GDP and international reserves data. Our estimation is performed in three steps. First, we estimate

\footnotetext{
2 We do not attempt to account for reserve accumulation in China, for two reasons. First, China maintained capital controls and a fixed exchange rate during the Asian Financial Crisis, and a major financial crisis did not occur in China. Second, Jeanne (2013) argues that China is a "semi-open" economy: its official sector has access to the international financial markets whereas the private sector does not. The official sector uses reserve accumulation as an
} 
the model parameters using maximum likelihood estimation. Based on an observational equivalence result (Hansen et al., 1999; Appendix B of our paper), there is a continuum of pairs of discount factor $(\beta)$ and concern for model misspecification parameter $(\theta)$ which yield the same likelihood. Second, we perform a structural break test and confirm that there is a break at the Asian Financial Crisis period. The break can be decomposed into the change in model uncertainty alone, which is governed by $(\beta, \theta)$, and other changes pertaining to the first two moments of income. We do not make restrictions on the income process in our estimation, and, in this way, we let the data speak to what extent reserve accumulation is driven by model uncertainty or income volatility. Third, asset market data before the break are used to pin down $\theta$ before the break. This also identifies the discount factor $\beta$. Then, we make use of the identifying assumption that $\beta$, which is a deep parameter, does not change before and after the crisis to pin down $\theta$ after the crisis.

We find that (i) the value of $\theta$ decreases after the crisis which corresponds to an increase in the perceived amount of model uncertainty and (ii) the values of $\theta$ 's before and after the crisis are in line with commonly accepted detection error probabilities (Anderson et al., 2003) which are metrics for model uncertainty. This finding supports our argument that an upward jump in the perceived amount of model uncertainty was an important determinant of the rapid reserve accumulation following the crisis. Our structural approach thus enables a novel interpretation for the structural break following the Asian Financial Crisis which has been studied extensively in the literature (see Aizenman et al., 2007; Gerlach et al., 2006; Lee and Song, 2011. To check whether the results above extend to other crisis-affected countries, we also conduct an empirical analysis using Thai data and obtain similar results (reported in Appendix D).

In addition, we recognize the fact that many driving factors of macroeconomic dynamics are inherently unobservable and incorporate Bayesian learning into our framework (Cogley et al., 2007; Hansen et al., 2002). Hur and Kondo (2016) consider the effect of unobservable fundamentals and Bayseian learning on international reserve accumulation in a related setup. However, we also allow our economic agents to doubt specifications of their learning processes (Cogley et al., 2008; Ellison and Sargent, 2012; Hansen and Sargent, 2008b). We show that learning can work as a powerful additional amplification mechanism in our framework. This is because cautious economic agents distort the prior distribution in a way that makes them more pessimistic in their consumption-saving decision. In particular, we demonstrate that learning introduces an expectations-driven amplification channel which can have a strong and persistent effect on the international reserve accumulation.

We emphasize that a unique feature of this paper is our quantitative, model-driven estimation approach. As discussed above, we combine robust control theory and financial data in our estimation. This approach is different from empirical contributions which borrow insights from theoretical models and study reduced-form regression models.

International reserve accumulation has been studied extensively by researchers in the field of international macroeconomics, both empirically and theoretically. They have considered its role as a self-insurance or precautionary savings due to roll-over risk (Bianchi et al., 2016; Hur and Kondo, 2016; Jeanne, 2007; Jeanne and Rancière, 2011), investigated its connection to an export-led growth strategy (Dooley et al., 2003) and (Bernanke, 2005; Dooley et al., 2005), looked into tensions between mercantilistic and insurance motives (Aizenman and Lee, 2007) and (Aizenman and Lee, 2008; Beck and Weber, 2011; Calvo et al., 2012; Choi and Taylor, 2017; Ghosh et al., 2017), examined connections to financial instability (Obstfeld et al., 2010), explored it as a crisis-easing mechanism (Bussière et al., 2015; Dominguez et al., 2012), and probed its relationship to financial development and openness (Bacchetta et al., 2013; Benigno and Fornaro, 2012; He and Luk, 2017; Jeanne, 2013; Wen, 2011). To our knowledge, we are the first to formally apply the idea of model uncertainty to understand the surge in international reserves after the Asian Financial Crisis.

The paper is structured as follows: Section 2 introduces our model. Section 3 estimates the model and provides evidence for a structural break during the Asian Financial Crisis. We provide a model uncertainty interpretation to this structural break. Section 4 incorporates learning into our framework and demonstrates its importance. Section 5 concludes and lays out future research directions.

\section{Model}

We consider a situation in which the social planner, who allocates her income between consumption and saving in the form of international reserves, recognizes the possibility that her model may be misspecified. To cope with this, she formulates a policy by applying robust control theory (Hansen and Sargent, 2008a) to address her concern for model misspecification. Following Hansen et al. (1999) we interpret the multiplicity of possible models as Knightian Uncertainty (Knight, 1921) which corresponds to a situation in which a decision-maker does not know for sure which probability distribution characterizes a model she ought to solve. This is distinct from "risk" which assigns a unique probability distribution as a model to be solved. ${ }^{3}$

instrument to force the private sector to save. Such a policy has the effect of reducing demand for non-tradable goods in China and thus stabilizing the real exchange rate. Our model does not have these institutional features.

3 Rietz (1988) and Barro (2006) use probability distributions with fat tails for large economic disasters to tackle a related issue that implausibly high values of the coefficient of relative risk aversion are required to rationalize the excess return of equity over bonds (i.e., equity premium puzzle). The difference between their approach and robust control theory is that whereas the former is concerned with risk, the latter is concerned with uncertainty. Moreover, the worst case model or probability distribution under robust control is determined by solving a relevant optimal control problem (see Section 2.2). Even though the two approaches are philosophically different, they both resolve the equity premium puzzle and other related issues by making the stochastic discount factor more volatile (see Cochrane, 2016). 
In the following, we use Hansen et al. (1999) permanent income model. We do this for three reasons. First, their model is well-known. Using a simple and known model allow us to focus on our empirical contribution. Second, in the literature, stylized models are commonly used to capture key features in small open economies and reserve accumulation. For instance, it is standard to use the standard linear-quadratic permanent income model by Hall (1978) to study the current account in a small open economy. For instance, Luo et al. (2012) incorporate robustness and rational attention in a small open economy permanent income model. Jeanne and Rancière (2011) study optimal reserve accumulation in a stylized model with an exogenous income process and an exogenous sudden stop risk. Our work is in the spirit of these models. Third, the downside of using this simple model is that we will not be able to explicitly model the specific economic institutions in the crisis-affected countries. But, we believe that our empirical finding is likely to hold in a more elaborate model setting. We will discuss this later.

\subsection{Baseline model}

First, we introduce a baseline or approximating model of the social planner to which a set of possible misspecifications will be introduced and from which a robust optimal policy will be derived. In the approximating model, the social planner solves ${ }^{4}$

$$
\max _{c_{t}} E_{0} \sum_{t=0}^{\infty} \beta^{t}\left[-\left(c_{t}-\mu_{b}\right)^{2}\right]
$$

subject to the resource constraint

$$
s_{t+1}=R s_{t}+d_{t}-c_{t},
$$

where $c_{t}$ is a consumption, $s_{t}$ is international reserves, and $d_{t}$ is an income which follows a stationary stochastic process. $E_{0}$ is the mathematical expectation conditional on time 0 information set, $\beta$ is the usual time discount factor, $\mu_{b}$ is the bliss point of the consumption, and $R$ is a fixed gross interest rate on the international reserves.

The income $d$ follows

$$
d_{t+1}=\check{d}_{t+1}+\phi_{s} s_{t+1},
$$

where $\check{d}$ is an exogenous stochastic process and $\phi_{s}$ captures the direct effect of the international reserves $s_{t+1}$ on the income. $\phi_{s} s_{t+1}$ in Eq. (3) is motivated by recent empirical studies which report various statistical relationships between international reserve accumulation and economic growth (Fukuda and Kon, 2010) and a positive relationship between international reserve accumulation relative to short-term debt or GDP before the crisis of 2008 and economic and financial performance during and after the crisis (Bussière et al., 2015; Dominguez et al., 2012).

Following Hansen et al. (1999), we model $\check{d}$ as a two-factor process

$$
\check{d}_{t+1}=\mu_{d}+d_{t+1}^{*}+\hat{d}_{t+1},
$$

where the factors $d^{*}$ and $\hat{d}$ follow stationary autoregressive processes with zero means and $\mu_{d}$ gives the unconditional mean of $\check{d}$. This allows us to study the effect of both persistent and transitory income shocks on the reserve accumulation. In Section 3, it will be shown that the estimated model is consistent with this motivation as one income factor is significantly more persistent than the other and the resulting impulse response functions are markedly different. Combining Eqs. (3) and (4) gives the income generating process

$$
d_{t+1}=\mu_{d}+d_{t+1}^{*}+\hat{d}_{t+1}+\phi_{s} s_{t+1} .
$$

It will be shown in Section 3.1 that the likelihood values computed using the actual data suggest a second order autoregressive process for the income factors $d^{*}$ and $\hat{d}$ in Eq. (4). Formally, they are written as

$$
\begin{aligned}
& \left(1-\phi_{1} L\right)\left(1-\phi_{2} L\right) d_{t+1}^{*}=\sigma_{d^{*}} \varepsilon_{t+1}^{d^{*}} ; \\
& \left(1-\alpha_{1} L\right)\left(1-\alpha_{2} L\right) \hat{d}_{t+1}=\sigma_{\hat{d}} \varepsilon_{t+1}^{\hat{d}},
\end{aligned}
$$

where $\varepsilon$ 's are independent Gaussian white noises with a zero mean and a unit variance and $L$ is the lag operator. The parameters $\sigma_{d^{*}}$ and $\sigma_{\hat{d}}$, which are non-negative, govern the amount of noise in the approximating model.

Private sector activities related to international reserve accumulation are not explicitly modeled here because we focus on the government's optimal international reserve policy instead. But, it is worth noting that the parameter $\phi$ and the income factors $d^{*}$ and $\hat{d}$ in Eq. (5) reflect unmodeled private sector financial and production decisions, and they interact with the reserve policy through Eq. (2). We leave it to a future exploration the microfoundation of $\phi$ and explicit characterizations of interactions between government's reserve policy and private agents' financial decisions in the context of our paper.

\footnotetext{
${ }^{4}$ Here, we use a quadratic utility function to keep the model tractable which is also common practice in the robust control literature (see Hansen and Sargent, 2008a. This also reduces computational costs substantially which facilitates the estimation of our model. There are now techniques available to approximate preferences other than quadratic ones accurately. For instance, see Anderson et al. (2012) and Ellison and Sargent (2015).
} 


\subsection{Robustness}

As mentioned at the beginning of the section, the social planner solves her optimal consumption/saving problem under model uncertainty. Given a set of models centered around her approximating model (1), (2), and (5), she formulates and implements a policy that is robustly optimal within this set. In this section, we show what this means and how it is carried out via robust control.

We rewrite the approximating model in the form of a general linear-quadratic control problem. First, we recast the instantaneous utility function as $-y_{t}^{\prime} M y_{t}-u_{t}^{\prime} Q u_{t}$ and the transition law as

$$
y_{t+1}=A y_{t}+B u_{t}+C \varepsilon_{t+1},
$$

where $y_{t}=\left[1, s_{t}, d_{t}^{*}, d_{t-1}^{*}, \hat{d}_{t}, \hat{d}_{t-1}\right]^{\prime}$ is a state vector, $u_{t}=\mu_{b}-c_{t}$ is a control variable, and $\varepsilon_{t+1}=\left[\varepsilon_{t+1}^{d^{*}}, \varepsilon_{t+1}^{\hat{d}}\right]^{\prime}$ is an independent white noise vector whose mean and variance are a zero vector and an identity matrix respectively. $Q, M, A, B$, and $C$ are defined in Appendix A.

However, the social planner does not have full confidence that Eq. (8) represents the true transition law. Following Hansen and Sargent (2008a), we assume that she considers a set of models

$$
y_{t+1}=A y_{t}+B u_{t}+C\left(\varepsilon_{t+1}+w_{t+1}\right),
$$

where each alternative or distorted model is indexed by $w$ : it is the distortion to the conditional mean of $\varepsilon .^{5}$ Hansen and Sargent (2008a) use the discounted conditional relative entropy to measure the size of this set. When $\varepsilon$ is Gaussian, the set takes the form

$$
E_{0} \sum_{t=0}^{\infty} \beta^{t+1} w_{t+1}^{\prime} w_{t+1} \leq \eta_{0},
$$

where the left-hand-side is the entropy measure and $\eta_{0}>0$ gives the upper bound for departures from the approximating model. A higher value of $\eta_{0}$ corresponds to a larger set of distorted models up for consideration. Augmenting (10) into the objective function, the social planner's robust control problem is given by

$$
\max _{\left\{u_{t}\right\}} \min _{\left\{w_{t+1}\right\}} E_{0} \sum_{t=0}^{\infty} \beta^{t}\left(-y_{t}^{\prime} M y_{t}-u_{t}^{\prime} Q u_{t}+\theta \beta w_{t+1}^{\prime} w_{t+1}\right)
$$

subject to the transition law (9). Hansen and Sargent (2008a) show that the parameter $\theta$ in (11), which is the Lagrange multiplier for the constraint in (10), is inversely related to $\eta_{0}$ in (10). A lower value of $\theta$ corresponds to a larger set of distorted models or misspecifications against which the social planner seeks robustness. The max-min preference in (11) captures the idea that the social planner copes with her model misspecification problem by choosing a policy that maximizes her worst-case scenario. ${ }^{6}$ This is the definition of a robust optimal policy in our setting.

As shown by Hansen and Sargent (2008a), the solution to this problem is given by

$$
u_{t}=-F y_{t} \text { and } w_{t}=K y_{t},
$$

where

$$
\begin{aligned}
& F=\beta\left(Q+\beta B^{\prime} D(P) B\right)^{-1} B^{\prime} D(P) A, \\
& K=\theta^{-1}\left(I-\theta^{-1} C^{\prime} P C\right)^{-1} C^{\prime} P(A-B F),
\end{aligned}
$$

and $P$ and $D(P)$ are obtained from solving the Riccati equations

$$
\begin{aligned}
& D(P)=P+\theta^{-1} P C\left(I-\theta^{-1} C^{\prime} P C\right)^{-1} C^{\prime} P, \\
& P=M+\beta A^{\prime} D(P) A-\beta^{2} A^{\prime} D(P) B\left(Q+\beta B^{\prime} D(P) B\right)^{-1} B^{\prime} D(P) A .
\end{aligned}
$$

The matrix $D(P)$ in (15) is the value matrix of the inner minimization problem in (11). As $\theta \rightarrow \infty$, which corresponds to the case without concern for misspecification of the transition law in (9), Eq. (15) converges to $P$. This reduces Eq. (16) to the usual Riccati equation for an ordinary linear-quadratic dynamic programming problem. ${ }^{7}$

\footnotetext{
5 We do not consider the distortion of the variance of $\varepsilon$ here because it does not influence the optimal policy: it only affects the welfare evaluation by introducing an additive constant term to the value function. Hansen and Sargent (2008a) refer to this result as the modified certainty equivalence. The implication is that the solution to the stochastic robust control problem in Eq. (11) can be obtained from solving the deterministic counterpart.

6 Gilboa and Schmeidler (1989) provide the axiomatization of the max-min preference in a similar context. Klibanoff et al. (2005, 2009) show that the max-min preference is a limiting case of the smooth ambiguity preference.

7 As shown in Hansen and Sargent (2008a), the value of $\theta$ cannot be too low because below the "breakdown" point, the objective function diverges to $-\infty$ : no attempt at maximizing the objective function is fruitful below this point because the worst case scenario that the social planner is confronted with is overwhelming.
} 
120

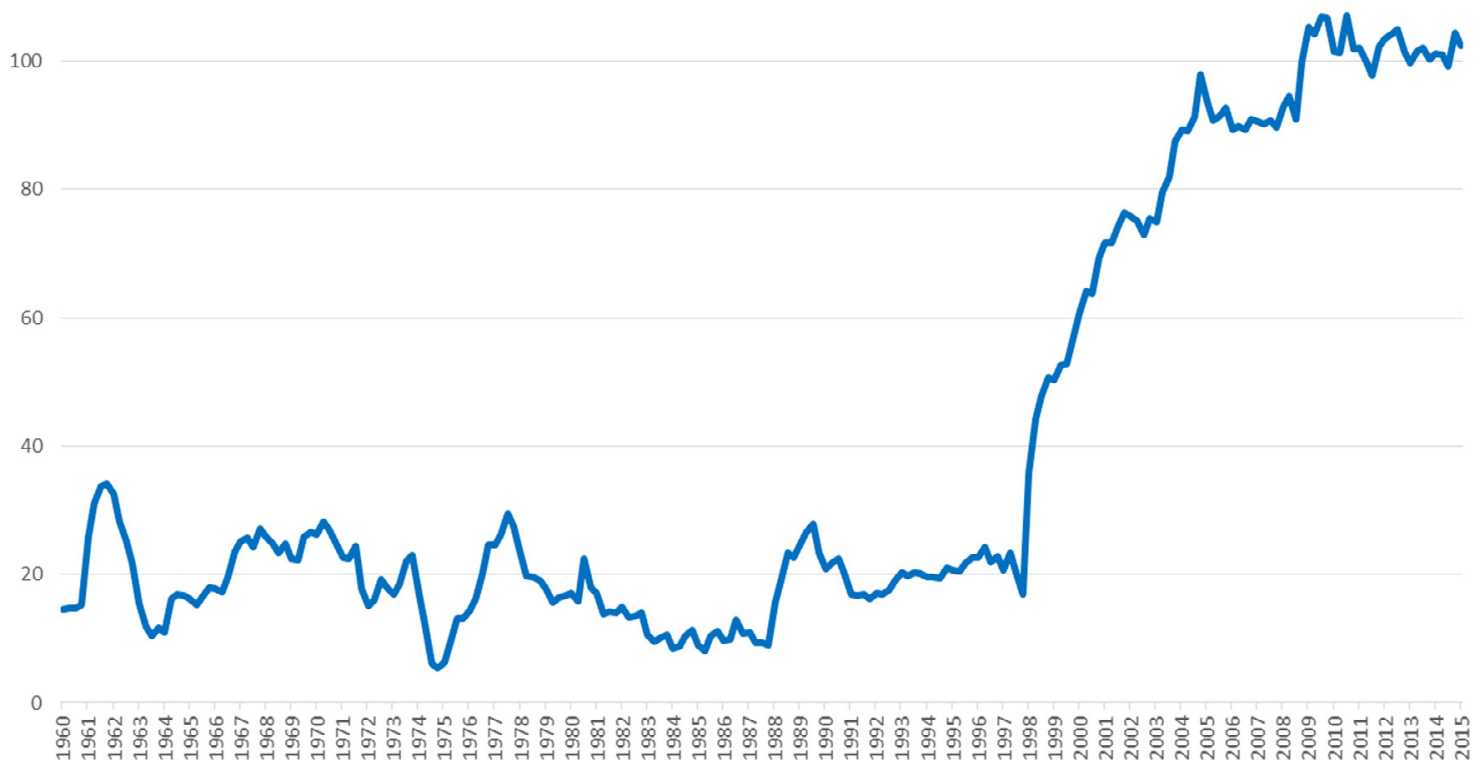

Fig. 2. Ratio of quarterly international reserves to quarterly GDP in Korea (in \%).

It is also worth emphasizing that a precautionary saving motive emerges in our model as a result of robust controlling against model uncertainty. Otherwise, the volatility matrix $C$ does not enter Eqs. (13), (15), and (16) due to the linearquadratic structure of the model. In this case, the solution is characterized by the certainty-equivalence principle whose implication is the absence of precautionary savings. Therefore, it is the model uncertainty (and the associated concern for model misspecification), not risk, that drives the precautionary saving motive in our model.

\section{Estimation and inference}

In this section, we will use the optimal policy in (12) to analyze international reserve accumulation in Korea before and after the Asian Financial Crisis. Fig. 2 plots the ratio of quarterly real international reserves to quarterly real GDP in Korea. It suggests a sharp break in the reserve-to-GDP ratio following the crisis in 1997. This is in line with the observation in Fig. 1 which is based on annual data. In what follows, this potential break point will be formally investigated based on the estimated model. Our estimation is divided into the following three steps.

In the first step, we estimate our model using maximum likelihood. However, as shown by Hansen et al. (1999), our model is characterized by an observational equivalence result: the optimal policy under $\beta=\bar{\beta}$ and $\theta=\infty$ is identical to the optimal policy under $\beta=\hat{\beta}(\theta)$ and $\theta<\infty$ where $\hat{\beta}(\theta)<\bar{\beta}$ and increasing in $\theta$, holding other parameters constant. Recall that a decrease in the uncertainty parameter $\theta$ translates to a larger set of model misspecifications against which the social planner seeks robustness. This creates a precautionary saving motive whose effect is mechanically similar to an increase in the discount factor $\beta$, as far as the optimal policy is concerned. This is why the effect of a decrease in $\theta$ can be offset by an appropriate decrease in $\beta$. It follows that the quantity implications of the model are invariant under the observationally equivalent pairs of the parameters. Hence, we estimate the case with $(\beta, \theta)=(\bar{\beta}, \infty)$ for the purpose of calibrating the model parameters. Appendix B provides the proof of the observational equivalence theorem applicable to our setting.

In the second step, we explicitly test whether there is a structural break at the time of the Asian Financial Crisis. Among other things, our estimation results show that $\bar{\beta}$ increases after the crisis. This is related to a rise in the social planner's perceived amount of model uncertainty which is investigated in the third step. We also discuss the implication of the structural break on income volatility.

In the third step, we use Korean asset market data before the crisis to calibrate $(\beta, \theta)$ such that these values are consistent with the estimate of $\bar{\beta}$ before the crisis. Our identification of $\theta$ after the crisis exploits the assumption that the discount factor $\beta$ is a deep parameter and is unchanged after the crisis. This step is in the same vein as Hansen et al. (2008) even though we focus on uncertainty as opposed to risk. We show that the decrease in $\theta$ after the crisis and the corresponding increase in model uncertainty are reasonable in terms of detection error probability and lead to large and persistent accumulation of international reserves. 


\section{Quarterly Detrended Real GDP and Real International Reserves (in Billion USD)}

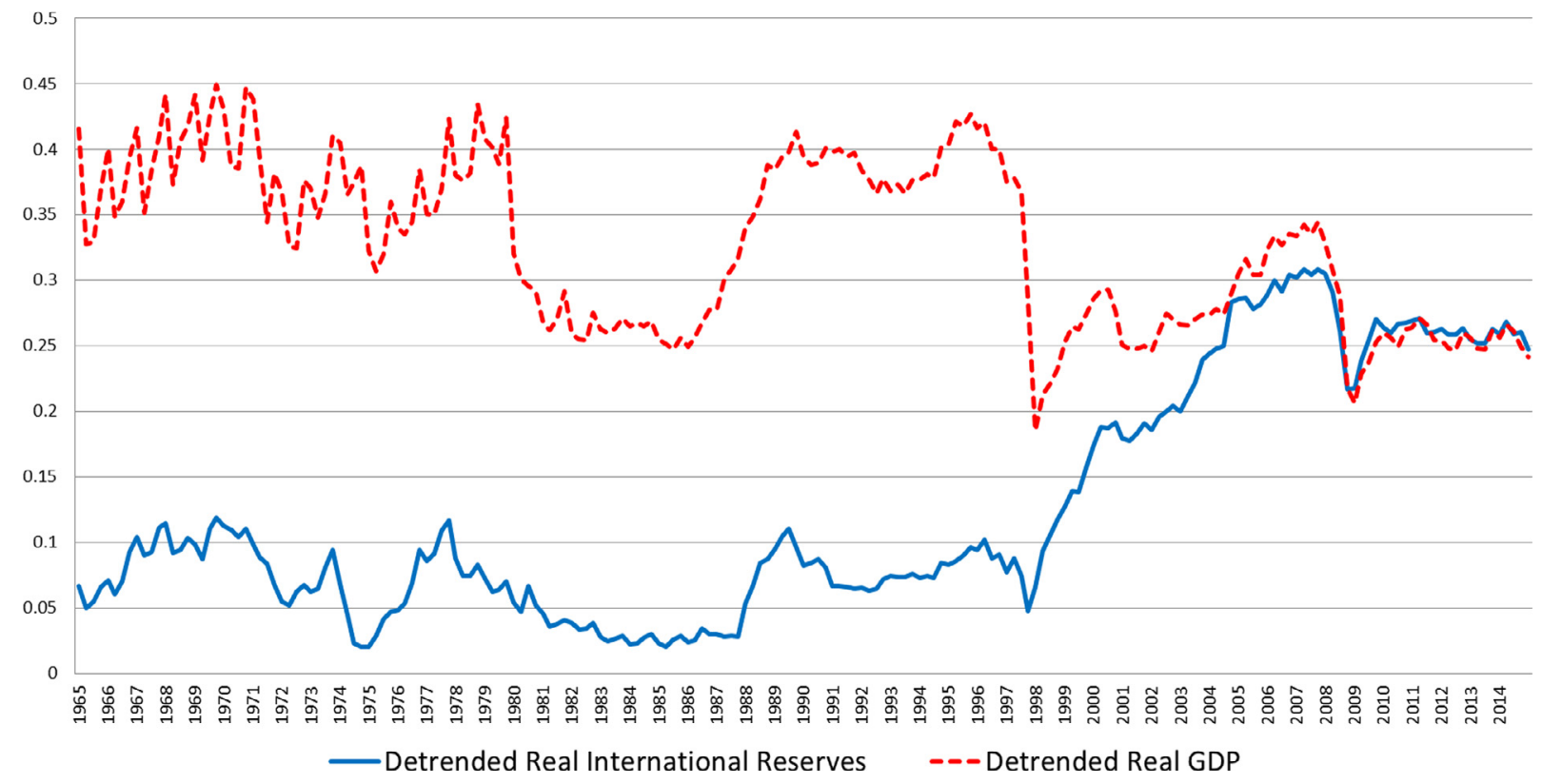

Fig. 3. Quarterly detrended real GDP and real international reserves for Korea (Q1:1965 to Q1:2015).

\subsection{Estimation based on the whole sample}

We exploit the observational equivalence result and estimate the model by maximum likelihood. The gross interest rate on the international reserves $R$ is fixed at 1.0103 which is the average (imputed) quarterly US real interest rate in this period. ${ }^{8}$ The bliss point for the consumption service stream $\mu_{b}$ is fixed at $0.5 .^{9}$ The estimated parameters are $\bar{\beta}$ (the time discount factor), $\mu_{d}$ (the constant in the income process), $\phi_{1}, \phi_{2}, \alpha_{1}$, and $\alpha_{2}$ (the autoregressive roots of the factors of the income process), $\sigma_{d^{*}}$ and $\sigma_{\hat{d}}$ (the standard deviations of the shocks to the factors of the income process) and $\phi_{s}$ (the direct effect of the international reserves on the income). The Kalman filter, which is used to evaluate the likelihood, is initialized at the steady state.

We use South Korean detrended real GDP and real international reserves data from Q1:1965 to Q1:2015 for estimation. These series are plotted in Fig. $3 .^{10}$ The average growth rate of the real GDP in the sample was used for detrending the data in a manner similar to Hansen et al. (1999). ${ }^{11}$ By inspection, the rapid surge in the international reserves from the fourth quarter of 1997 onward suggests a structural break could have occurred in the neighborhood of the Asian Financial Crisis. This, together with the determination of the break point, will be investigated formally in Section 3.2.

Because we have two shocks (see Eqs. (6) and (7)) for two observables, we can avoid stochastic singularity without adding measurement errors to the observation equations of the Kalman filter Ruge-Murcia, 2007). The likelihood is numerically maximized using the optimization software of Chris Sims. ${ }^{12}$

Table 1 provides the estimates based on the whole sample. Whereas the income factor $d^{*}$ contains a highly persistent autoregressive root $\left(\phi_{1}=0.9824\right)$, the income factor $\hat{d}$ contains autoregressive roots that are not very persistent

\footnotetext{
8 The US real interest rate data are taken from the World Bank database (http://data.worldbank.org/indicator/FR.INR.RINR). The data are at annual frequency.

${ }^{9}$ As Hansen et al. (1999) show, the value of $\mu_{b}$ is not fundamental to the analysis here. However, given that $\mu_{b}$ appears in Eq. (18), we set it to a number that (a) is large enough so that it fulfills our understanding of the bliss point as a long-run consumption state, (b) allows the estimated steady state ratio of real international reserves to real GDP to be close enough to the average ratio in the pre-break data, and (c) tracks the level of real GDP reasonably well. In our view, $\mu_{b}=0.5$ is the choice that delivers a reasonable compromise among the three objectives.

10 The data are obtained from the International Monetary Fund International Financial Statistics. For reserves, we use the stock of total international reserves series. During the sample period, gold constitutes less than $1 \%$ of total reserves and this does not affect our analysis.

11 The average growth rate of the real GDP in the sample is $1.31 \%$. The data are detrended by multiplication of $1.0131^{-t}$ where $t=0,1,2, \ldots$ This detrending scheme allows us to capture the downward shift in real GDP following the Asian Financial Crisis (as is evident from Fig. 3 ) as a stylized fact. It also produces a conservative estimate of the increased perception of model uncertainty after the crisis: if we detrend real GDP in such a way that it is stationary throughout the sample, the model uncertainty parameter is forced to do more work and the resulting increase in the perceived level of model uncertainty is more pronounced. Note that the detrending method here does not change the ratio of international reserves to GDP in the original series in Fig. 2.

12 It is available on the personal website of Chris Sims (http://sims.princeton.edu/yftp/optimize/).
} 
Table 1

Estimates (based on the whole sample from Q1:1965 to Q1:2015).

\begin{tabular}{lll}
\hline Parameter & Value & Explanation \\
\hline $\bar{\beta}$ & 0.9834 & Time discount factor \\
$\mu_{d}$ & 0.4999 & Constant in the income process \\
$\phi_{1}$ & 0.9824 & Autoregressive root of factor 1 \\
$\phi_{2}$ & -0.0931 & Autoregressive root of factor 1 \\
$\alpha_{1}$ & 0.0510 & Autoregressive root of factor 2 \\
$\alpha_{2}$ & 0.1350 & Autoregressive root of factor 2 \\
$\sigma_{d^{*}}$ & 0.0269 & Standard deviation of the shocks to factor 1 \\
$\sigma_{\hat{d}}$ & 0.0110 & Standard deviation of the shocks to factor 2 \\
$\phi_{s}$ & 0.0262 & Effect of international reserves on income \\
\hline
\end{tabular}

Table 2

Likelihood values.

\begin{tabular}{ll}
\hline Order & Likelihood values \\
\hline 1 & 1266.12 \\
2 & 1270.54 \\
3 & 1270.54 \\
\hline
\end{tabular}

$\left(\alpha_{1}=0.0510, \alpha_{2}=0.1350\right){ }^{13} d^{*}$ also has a larger standard deviation for its shock than $\hat{d}\left(\sigma_{d *}=0.0269, \sigma_{\hat{d}}=0.0110\right)$. So, the income process is characterized by one of its factors being both more persistent and noisier than the other. As mentioned in Section 2.1 above, we model the income factors as autoregressive processes and select their lag orders by comparing likelihood values under different specifications. Table 2 gives the values of the maximized likelihood for autoregressions of order 1,2, and 3. It shows that there is a clear gain from moving to order 2 from order 1, but (practically) no gain from moving to order 3 from order 2 . We use this evidence as the justification for choosing order 2 .

In the next section, we will use these full-sample estimates and the corresponding maximized likelihood to test for structural breaks in the neighborhood of the Asian Financial Crisis.

\subsection{Structural breaks and dynamic implications}

As Fig. 3 above indicates, the international reserve accumulation in Korea changed dramatically in the aftermath of the Asian Financial Crisis. In this section, we investigate this observation formally using the Andrews test (Andrews, 1993; 2003). We choose this test over other tests of structural breaks ${ }^{14}$ because it does not require the definite knowledge of break points: Given a set of possible break points, a set of corresponding test statistics is computed and the supremum of this set is used for statistical analysis. This supremum test statistic has a distribution which departs from the conventional $\chi^{2}$-distribution. In what follows, we consider the window of time from Q3:1995 to Q1:2000 and allow all estimated parameters (listed in Table 3) to change in order not to force the result to be driven by changes in only subsets of the parameters. ${ }^{15}$

Fig. 4 plots the likelihood ratio statistics at the aforementioned possible break points. The likelihood ratio statistic is two times the difference between (a) the sum of the likelihoods based on the pre-break sample and the post-break sample and (b) the likelihood based on the whole sample. The supremum of these statistics, which is also the test statistic here, occurs in Q4:1997 which includes the date on which Korea availed of the IMF rescue package (December 3, 1997). As the figure shows, the null hypothesis of no break is rejected at a significance level below $1 \%$. This result is robust to using different windows of time. In what follows, we take Q4:1997 as the break point in our sample. Table 3 provides parameter estimates based on the pre-break sample, the post-break sample, and the whole sample.

Given these estimated parameters, we can ask how the structural change impinges on the dynamics of our model. We answer this question by first studying the long-run implication of the structural change. The steady-state level of the international reserves is given by

$$
\bar{s}=\frac{\mu_{d}-\mu_{b}}{1-\left(R+\phi_{s}\right)} .
$$

\footnotetext{
${ }^{13}$ While estimates of the autoregressive root $\phi_{1}$ here and subsequently are close to unity, we follow Hansen et al. (1999) and do not to restrict them to be unit roots. The possible existence of a unit root in the system does not affect its numerical stability because the stability condition requires that an eigenvalue of the optimal transition law is less than $|1 / \sqrt{\bar{\beta}}|>1$.

14 See Lütkepohl (2009) for a survey of tests of structural breaks in the context of vector autoregressive models.

15 It is possible that there is another structural break in Q4:2008. But since the power of the Andrews test is low towards the end of the sample period, we do not perform a structural break test around the crisis in 2008. We leave this for future research when more data will be available.
} 
Table 3

Whole sample and sub-sample estimates for Korea.

\begin{tabular}{llll}
\hline Parameter & Before the break & After the break & Whole sample \\
\hline $\bar{\beta}$ & 0.9814 & 0.9912 & 0.9834 \\
$\mu_{d}$ & 0.4975 & 0.4822 & 0.4999 \\
$\phi_{1}$ & 0.9765 & 0.9985 & 0.9824 \\
$\phi_{2}$ & -0.1500 & 0.0304 & -0.0931 \\
$\alpha_{1}$ & 0.3995 & -0.0949 & 0.0510 \\
$\alpha_{2}$ & -0.2539 & 0.4703 & 0.1350 \\
$\sigma_{d^{*}}$ & 0.0296 & 0.0159 & 0.0269 \\
$\sigma_{\hat{d}}$ & 0.0108 & 0.0109 & 0.0110 \\
$\phi_{s}$ & 0.0339 & 0 & 0.0262 \\
\hline
\end{tabular}

The whole sample ranges from Q1:1965 to Q1:2015. Q4:1997 is selected as the break point based on the Andrews test. Table 1 provides explanations about the parameters.

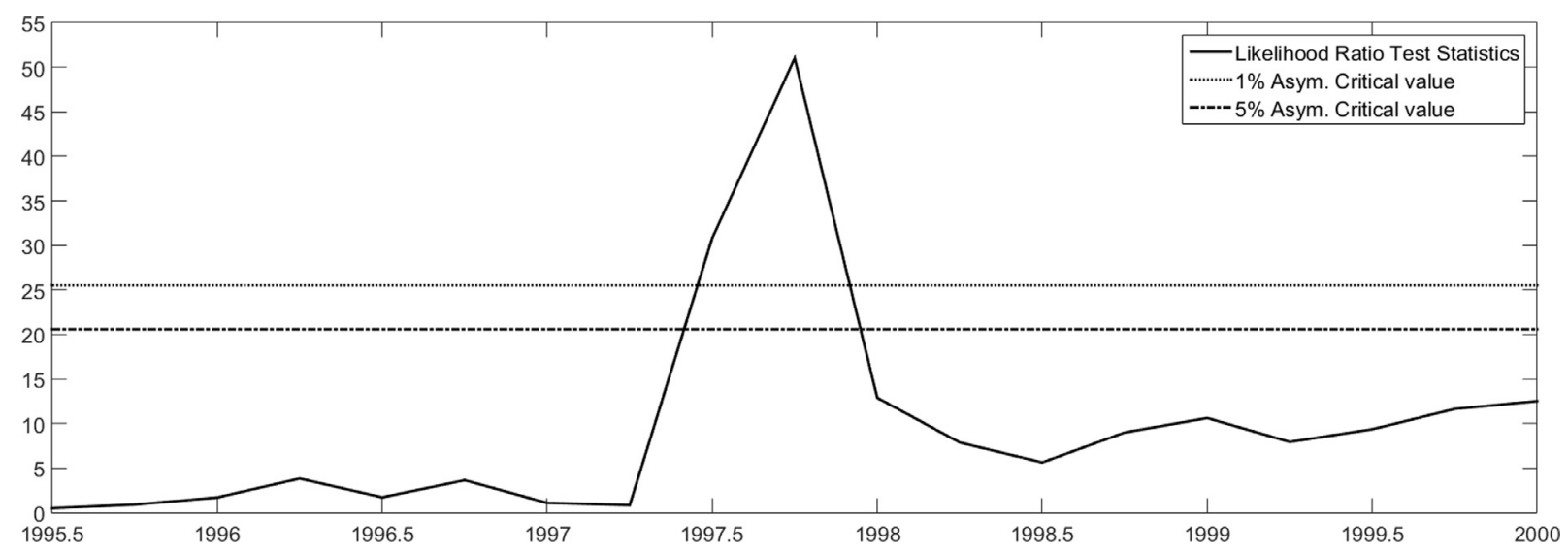

Fig. 4. $2 \times$ Likelihood ratios and Andrews supremum test. The horizontal axis denotes break points. $0,0.25,0.5$, and 0.75 that follow years (from 1995 to 2000) correspond to Q1, Q2, Q3, and Q4 of those years respectively (e.g., 1995.5 is Q3:1995). The solid line plots twice the value of the likelihood ratio statistic which is the difference between (a) the sum of the likelihoods based on the pre-break sample and the post-break sample and (b) the likelihood based on the whole sample. The critical values of the Andrews supremum test are obtained from (Andrews, 1993; 2003). The fine dashed line gives the 1\% critical value and the coarse dashed line the $5 \%$ critical value.

It increases from 0.0565 billion USD to 1.7229 billion USD after the structural break due to the decline in $\mu_{d}$ (row 2 of Table 3 ) and $\phi_{s}$ (last row of Table 3 ). The latter facilitates the precautionary savings interpretation of the reserve accumulation (i.e., the social planner accumulates international reserves even though they no longer have any direct income effect). The steady-state international reserves to quarterly GDP ratio is given by

$$
\frac{\bar{s}}{\bar{d}}=\frac{\mu_{d}-\mu_{b}}{\mu_{d}(1-R)-\phi_{s} \mu_{b}},
$$

and this ratio increases from $11 \%$ to $357 \%$ (or $89 \%$ as a fraction of annual GDP). Thus, the rapid surge in the international reserves in Fig. 3 can be understood in part as a response to this long-run change. Eqs. (17) and (18) are derived in Appendix C.

As we explain below, we focus on the change in the discount factor $\bar{\beta}$ alone in the paper. Because this does induce an accompanying change in the steady state as Eqs. (17) and (18) show, our results are not sensitive to whether the post-break steady state is reasonable or not. Moreover, when we calibrate $\mu_{b}$ to match the pre-break ratio of international reserves to GDP, the estimates of $\bar{\beta}$ before and after the break change only slightly.

To see how the structural change alters dynamic response of the international reserves to the income factor shocks, we compare the impulse response functions of the model evaluated at the pre-break estimates to those at the post-break estimates. As explained at the beginning of Section 3, the observational equivalence result implies that an increase in the discount factor $\beta$ works like a decrease in the uncertainty parameter $\theta$ which leads the social planner to entertain a larger set of model misspecifications. This makes us especially interested in the effect of a change in $\bar{\beta}$ alone. Hence, we analyze this case in addition to the two cases above. Technically speaking, we decompose the effect of the structural break into (a) the part due to the change in $\bar{\beta}$ alone and (b) the part due to the change in other parameters, including those related to income volatility.

Fig. 5 gives the impulse response functions of all the cases subject to a one standard deviation negative shock to $\varepsilon^{d^{*}}$ (shock to the persistent income factor) and $\varepsilon^{\hat{d}}$ (shock to the transitory income factor) respectively. We start all of them from the steady state associated with the pre-break estimates in order to facilitate comparison. The figure shows that international reserve accumulation under the model evaluated at the post-break estimates (labeled "All parameters change") responds 

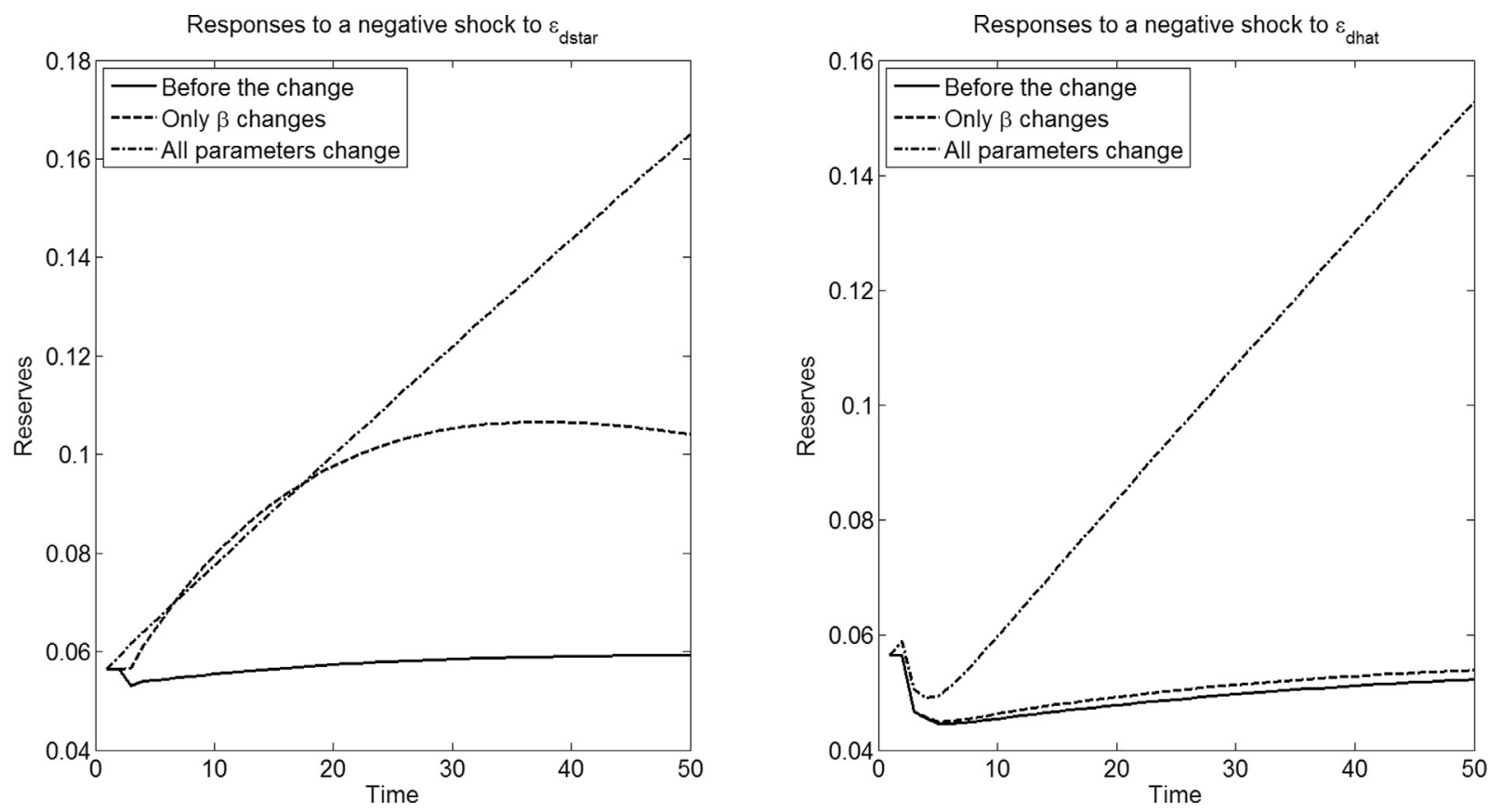

Fig. 5. Impulse response functions of international reserves. The impulse response functions are subject to a one standard deviation negative shock to the persistent income factor (left) and the transitory income factor (right). "Before the change" refers to the pre-break estimates, "Only $\beta$ changes" to the change in the discount factor only from the pre-break estimates, and "All parameters change" to the post-break estimates. All impulse response functions start from the steady state associated with the pre-break estimates.

more strongly relative to the one at the pre-break estimates (labeled "Before the change") subject to the negative income shocks. The former corresponds to scenarios in which the unexpected structural break is followed by the negative income shocks. The observed difference is partly due to the change in the steady state and partly due to the change in the policy function in the aftermath of the structural break. As shown in Eq. (17), only the income process parameters $\mu_{d}$ and $\phi_{s}$ in Eq. (5) affect the steady state level of international reserves ( $\mu_{b}$ and $R$ are fixed parameters). The change in the policy function additionally depends on the changes in the discount factor $\bar{\beta}$ and the roots of the income factors $\phi_{1}, \phi_{2}, \alpha_{1}$, and $\alpha_{2}$ as Eqs. (12)-(16) point out. However, it does not depend on the standard deviations of the income factor shocks $\sigma_{d^{*}}$ and $\sigma_{\hat{d}}$ due to the certainty equivalence principle. ${ }^{16}$ Nonetheless, the changes in the autoregressive roots and the standard deviations elevate the unconditional income volatility ${ }^{17}$ and alter the stochastic properties of the model. ${ }^{18}$ The impulse response function at the post-break estimates ("All parameters change") displays the sum of all these effects.

Moreover, Fig. 5 also shows that the increase in $\bar{\beta}$ alone (labeled "Only $\beta$ changes") accounts for a large portion of the observed difference in response to the shock to the persistent income factor (left panel).

This is due to the fact that the rise in $\bar{\beta}$, which increases the relative importance of the future utilities, makes the social planner more concerned about the persistent negative income shock. We find that the change in $\bar{\beta}$ dominates other parametric changes, including those related to the rise in income volatility. We emphasize again that our MLE estimation does not restrict the parameters governing the income process before and after the crisis, but it turns out that the rise in $\bar{\beta}$ is important in driving the increase in the reserves. This finding motivates us to focus on $\bar{\beta}$ in the next section. Recall that the parameter $\bar{\beta}$ has tight connection to model uncertainty due to the observational equivalence result (Hansen et al., 1999, Appendix B). In light of this, the dynamics under "Only $\beta$ changes" will be reinterpreted as the social planner's optimal response to the increased level of model uncertainty.

It is worth noting that a version of the baseline model with one stochastic income factor and one stochastic bliss point (see Hansen et al., 1997, which is one way to operationalize preference shocks similar to those considered by Albuquerque et al. (2016), is identical (up to sign) to the baseline model with two stochastic income factors above as far as model

\footnotetext{
${ }^{16}$ Recall that we exploit the observational equivalence result (Hansen et al., 1999, Appendix B) and impose $\theta=\infty$ for estimation. As discussed in Section 2.2, this implies that the certainty equivalence principle holds. Therefore, the optimal policy function does not depend on the volatility matrix $C$ which contains the standard deviations of the income factor shocks (see Appendix A.

17 The calculations based on the Yule-Walker equations show that whereas the unconditional variance of the persistent income factor increases from 0.0144 before the break to 0.0897 after the break, the unconditional variance of the transitory income factor is practically identical before and after the break (approximately 0.0001). As Table 3 reveals, the increase in the former is driven by the changes in the autoregressive roots.

18 The equilibrium transition law of the economy is obtained by substituting the optimal policy function $u$ in Eq. (12) into the transition law in Eq. (8). Hence, the volatility matrix $C$ matters for the stochastic properties of the model.
} 
dynamics are concerned. ${ }^{19}$ This is due to the isomorphism of the transition laws in the two models. It follows that the inference procedure for $\theta$ is not altered by considering this type of preference shocks.

\subsection{The Asian Financial Crisis and the increase in uncertainty}

We focus on the identification of $\bar{\beta}$ in this section. We ask the following question: suppose only $\bar{\beta}$ changes after the structural break (and other estimated parameters are held at the pre-break values). By how much $\theta$ should change in order to have the same effect as the change in $\bar{\beta}$ ? Under this approach, it is assumed that the discount factor $\beta$ is a deep parameter which is invariant over time as commonly accepted in the macroeconomics literature. So, the increase in $\bar{\beta}$ in Table 3 is interpreted as a decrease in $\theta$ instead. ${ }^{20}$ Therefore, the answer to this question allows us to think about the effect of the Asian Financial Crisis (a) on the perceived amount of model uncertainty the social planner faces and (b) the effect on the international reserve accumulation in turn.

As shown in Table 3, the estimate of $\bar{\beta}$ increases from 0.9814 to 0.9912 after the structural break. Using the observational equivalence result mentioned at the beginning of Section 3, we can back out the change in $\theta$ that leads to the same policy function as the one with $\beta$ at the post-break value. Through this exercise, we can gauge by how much the social planner's perceived amount of model uncertainty increased after the Asian Financial Crisis.

We make use of the equity premium in the Korean financial data to identify $\theta$ before the crisis. $^{21}$ Using the Korean stock market index (KOSPI) data and the bank discount rate data from Q1:1980 to Q3:1997, we compute the excess return of equity over safe asset before the crisis. This series gives the Sharpe ratio ${ }^{22}$ of 0.0712 which is consistent with the values from other empirical studies, for instance 0.08 from Park and Kim (2009). Then, we look for a tuple of $\beta$ and $\theta$ which is observationally equivalent to the pre-break estimates but also attains the Hansen-Jagannathan lower bound on the Sharpe ratio (Hansen and Jagannathan, 1991). We take the Hansen-Jagannathan bound as the minimum restriction that needs to be satisfied by an asset-pricing model. Using the observational equivalence formula (see Appendix B), we obtain $\beta=0.9566$ and $\theta=0.4129$. To check whether they are reasonable, we compute the detection error probability (Anderson et al., 2003)) based on these values. This is the probability with which the social planner misleadingly chooses the approximating model as the data-generating mechanism when the distorted model is the true data-generating mechanism and vice versa. ${ }^{23}$ We obtain detection error probability of 0.2473 , which is in close proximity to the range used in the literature. ${ }^{24}$

Next, in order to match $\bar{\beta}=0.9912$ after the crisis with $\beta=0.9566$, the discount factor before the crisis which we take to be invariant, we look for the value of $\theta$ that is observationally equivalent to the former. This yields $\theta=0.3409$, and the corresponding detection error probability of $0.1942 .{ }^{25}$ With this change, the detection error probability drops by about 5 percentage points, which means that the social planner is about $5 \%$ less likely to select the wrong model. This is because a substantial decrease in $\theta$ increases the set of model misspecifications against which the social planner seeks robustness, and the worst-case model is now discernibly worse than before. In light of this exercise, the surge in the international reserves in Korea in the aftermath of the Asian Financial Crisis can be understood as the optimal response by the social planner to guard against the downside of the more uncertain world. This is illustrated with "Only $\beta$ changes" in Fig. 5.

To summarize, the findings above indicate that the increase in model uncertainty was an important determinant of the surge in international reserves in the aftermath of the Asian Financial Crisis. Moreover, the new $\theta$ after the crisis corresponds to a reasonable detection error probability: it is well within the range used in the robust control literature. In contrast, a risk explanation would require agents to bear large coefficients of relative risk aversion as discussed in the introduction. ${ }^{26}$ Our finding thus supports the result of Barillas et al. (2009) that model uncertainty provides an empirically plausible alternative to risk. As shown by "All parameters change" in Fig. 5, the effect of model uncertainty on the reserve accumulation is reinforced by other parametric changes related to income volatility.

At the beginning of Section 2, we argued that our result is likely to extend to a more elaborate model. As demonstrated above, as long as an increase in $\bar{\beta}$ translates into a heightened concern about future utilities, the optimal response to a persistent negative income shock would produce a persistent increase in the reserve accumulation, even in the absence of other structural changes. Therefore, the result above will survive in a more complex model whose institutional features are related to the other parameters in our model. The increase in the perceived amount of model uncertainty in our setting is also qualitatively similar in effect to the increase in the estimated probability of a financial crisis in Hur and Kondo (2016).

\footnotetext{
19 Dynamic models with preference shocks are popular in the financial crisis/macro-finance literature. For instance, see Christiano et al., 2011.

20 If we had considered probabilistic transitions across different values of $\beta$ instead (e.g., low and high as in regime-switching models), the observational equivalence would continue to hold regime by regime: if we recover $\theta$ for a given value of $\beta$ in each regime, there will be a continuum of tuples of $\theta$ and $\beta$ that implement the same policy function. So, even in this case, some numbers have to be assigned to $\beta^{\text {low }}$ and $\beta^{\text {high }}$ as baseline values.

21 This is possible because the observational equivalence applies only to quantities, not prices. See Hansen et al., 1999.

22 The Sharpe ratio is defined as the ratio of the mean excess return to its standard deviation.

23 This is similar in spirit to controlling for Type 1 error at a particular confidence level for the purpose of decision-making. The detection error probability is used as a metric for model uncertainty in the robust control literature (see Hansen and Sargent, 2008a.

24 Barillas et al. (2009) recommend 20\% or less. Giordani and Soderlind (2004), Hansen et al. (2010), and Hansen and Sargent (2010) suggest between 10 and $20 \%$.

25 The corresponding stochastic discount factor is well within the Hansen-Jagannathan bound.

${ }^{26}$ As shown by Park and Kim (2009), analyzing the Korean financial data based on the Epstein-Zin preference (Epstein and Zin, 1991) still requires unreasonably high levels of risk aversion in order to attain the Hansen-Jagannathan bound.
} 


\section{Business Outlook (Manufacturing Firms)}

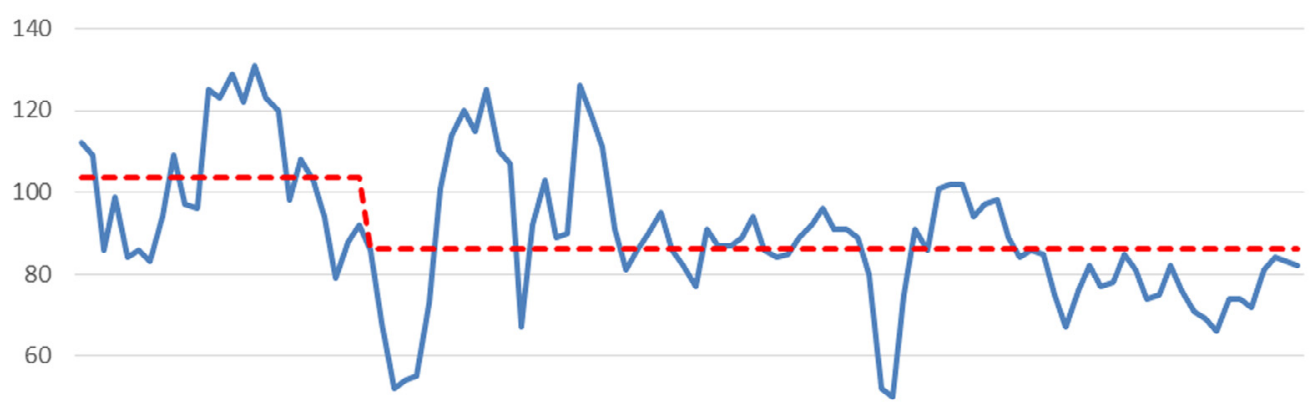

40

20

0

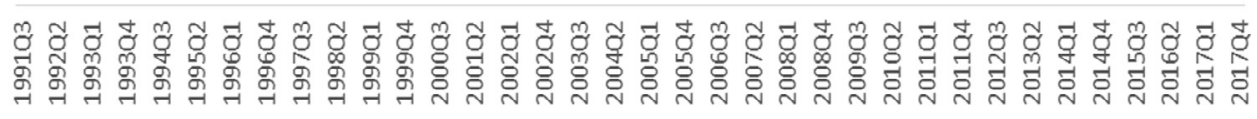

— Business Outlook - ----Business Outlook Means

Fig. 6. Business outlook of Korean manufacturing firms. Data source: Business Survey Index (BSI) for Korean manufacturing firms from 1991 to 2017 , Bank of Korea (various years). BSI asks one month ahead business outlook to surveyed firms, with 100 being the reference point. The value below 100 is interpreted as negative business outlook, and the value above 100 as positive outlook, with higher values corresponding to more favorable outlook. It is available from Q3:1991 onward, at quarterly frequency from 1991 to 2003 and at monthly frequency thereafter. Business Outlook Means are arithmetic means before and after Q4:1997 respectively.

However, the model uncertainty parameter $\theta$ in our model is formally estimated, and the associated worst case probability distribution is endogenously determined by solving the social planner's robust optimal policy problem.

Is there any other evidence consistent with our statistical analysis that there was a discrete upward jump in the social planner's perception of uncertainty in Korea following the Asian Financial Crisis? Fig. 6 displays Business Survey Index (BSI) (collected by the Bank of Korea) from 1991 to 2017. BSI surveys one month ahead business outlook of Korean firms, with 100 being the reference point. The value below 100 is interpreted as negative business outlook, and the value above 100 as positive outlook, with a higher value corresponding to more favorable outlook. Here, we focus on manufacturing firms (both conglomerate and non-conglomerate) because this is the most important sector of the Korean economy. Note that business outlook (solid line in blue) drops sharply following the Asian Financial Crisis: the average business outlook (dashed line in red) drops from 103.6 to 86.1 after Q4:1997. However, the standard deviations before and after the crisis are almost identical: they are both around 15.9. The findings are consistent with the effect of increased concern for model misspecification (i.e., a decrease in $\theta$ ) on expectations formation: the conditional mean shifts downward. ${ }^{27}$ The result is robust to seasonal adjustments.

Fig. 7 plots Korean manufacturing firms' (both conglomerate and non-conglomerate) asset to equity ratio from 1985 to 2015. The figure shows that (a) Korean firms engaged in deep restructuring of their corporate financial structures in the aftermath of the Asian Financial Crisis of 1997 and (b) the graduation from the IMF bail-out program in 2001 did not deter them from continued practice of more conservative financial management which can be seen from persistent increases in equity-financing of their assets well beyond 2001. Lim (2012) further shows that corporate asset to equity ratio and liquidity ratios improved for both conglomerate and non-conglomerate firms, and these changes allowed Korean firms to weather the global economic crisis of 2008 better. The persistent deleveraging by Korean manufacturing firms following the Asian Financial Crisis is consistent with the evidence from Fig. 6: more pessimistic business outlook, which ensued after the crisis, has induced more conservative financial management. ${ }^{28}$

\footnotetext{
27 As Bhandari et al. (2017) show, survey data on expectations enable direct estimation of the model uncertainty parameter $\theta$. Unfortunately, Korea does not have survey data on household and/or firm forecasts of concrete macroeconomic variables (e.g., unemployment and inflation) going back sufficiently to be useful for studying the Asian Financial Crisis. Whereas BSI does not survey expectations on concrete macroeconomic variables, it goes back sufficiently to be suitable for analyzing the Asian Financial Crisis (available from Q3:1991 onward), and it is also sufficiently informative to facilitate the qualitative inference concerning $\theta$ as discussed above. We would like to thank an anonymous referee for the suggestion to consider using survey data.

${ }^{28}$ The Economist featured an article which relates this phenomenon (it refers to this as "cash hoarding") to Korean firms' negative experiences with banks during the Asian Financial Crisis (http://www.economist.com/news/leaders/21620203-japanese-and-south-korean-firms-are-worldsbiggest-cash-hoarders-hurts-their). The article also connects a similar experience in Japan to the collapse of the financial bubbles in the early 90 s.
} 


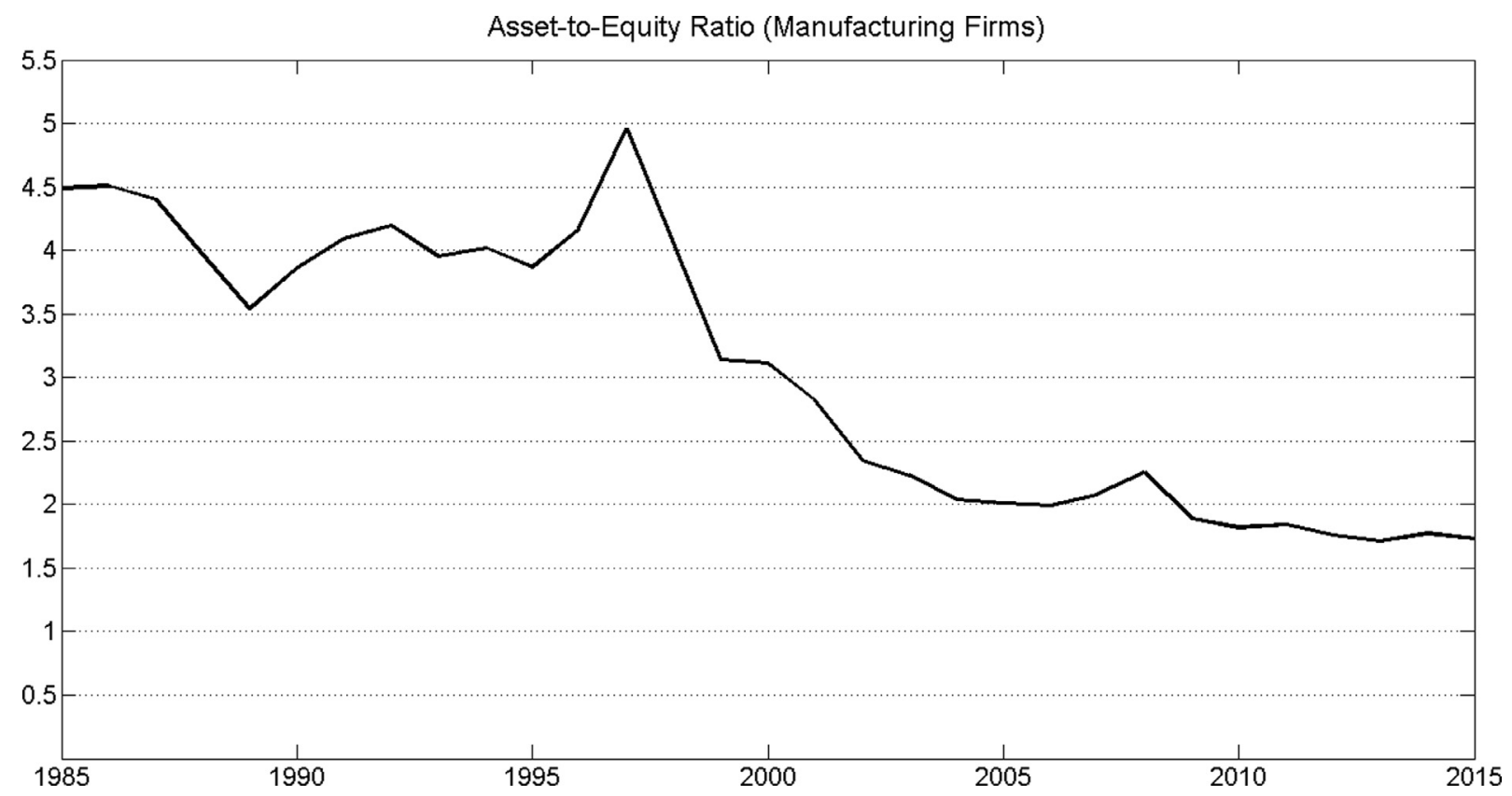

Fig. 7. Asset-to-equity ratio of Korean manufacturing firms data source: Debt-to-equity ratio data for Korean manufacturing firms from 1985-2015, Bank of Korea Financial Statement Analysis (various years). The data include corporations legally obligated to be audited by an independent external auditor. Asset-to-equity ratio $=1+$ debt/equity.

We leave it to a future investigation the structured analysis of the interactions among economic and financial uncertainty, government's international reserves and debt policy, sovereign spreads, and private sector financial and real activities. ${ }^{29}$ Bianchi et al. (2016) is a pioneering quantitative work on the relationships among international reserves, government debts, and sovereign spreads.

Appendix D applies the empirical analysis in this section to Thai data to ensure that our proposed mechanism also works for other economies affected by the Asian Financial Crisis. ${ }^{30}$

\subsection{Quantitative contribution of $\bar{\beta}$ under alternative calibrations}

How robust is the quantitative significance of the change in the discount factor $\bar{\beta}$ in accounting for the international reserve accumulation in Korea following the Asian Financial Crisis? In this section, we assess the robustness of our findings in Sections 3.2 and 3.3 by considering international reserve dynamics under alternative calibrations that match the steady state of the model to the time average in the data. ${ }^{31}$

In contrast to Section 3.2, here the bliss point $\mu_{b}$ is estimated to match the steady state reserve-to-GDP ratio (given in Eqs. (18)) to the average reserve-to-GDP ratio in the pre- and post-break sub-sample respectively. Table 4 provides the parameter estimates. The implied steady state reserve-to-GDP ratios are $19.26 \%$ for the pre-break period and $86.99 \%$ for the post-break period, which are off by less than one percentage point from the corresponding average ratios in the subsamples. The estimates also match the steady state levels of international reserves to the average levels in the sub-samples almost exactly.

To evaluate the quantitative importance of $\bar{\beta}$ under these alternative calibrations, we first subject our model to the structural break documented in Table 4 , and then a shock sequence (to the income factors) that increases the reserve-toGDP ratio from the pre-break steady state value to the post-break steady state value in 20 quarters. Then, we deactivate the quantitative contribution of the change in $\bar{\beta}$ by changing only $\bar{\beta}$ back to the pre-break value and subjecting the resulting

\footnotetext{
${ }^{29}$ In the context of the current analysis, the fall in sovereign spreads after the Asian Financial Crisis should not be used as evidence against the model uncertainty channel because the narrowing of the sovereign spreads can be an endogenous response to the increased reserve accumulation, which in turn is driven by the heightened concerns for model misspecification.

${ }^{30}$ To be specific, we carry out the first two steps of the empirical exercise discussed at the beginning of Section 3. These correspond to Sections 3.1 and 3.2 above. The last step, which is what Section 3.3 is about, is skipped because (a) we are constrained by the relatively shorter sample size of Thai financial data and (b) we believe that the pre-crisis dynamics in the Thai financial data require a separate analysis which is beyond the scope of the paper. In general, we are constrained by data limitations (e.g., sample size, data reliability) to apply the empirical analysis in this section in its entirety to other countries that were also severely affected by the Asian Financial Crisis. For instance, see the IMF Staff Country Report for Indonesia (No. 05/255).

31 We would like to thank an anonymous referee for suggesting this quantitative exercise.
} 
Table 4

Estimates matching the reserve-to-GDP ratios.

\begin{tabular}{lll}
\hline Parameter & Before the break & After the break \\
\hline $\bar{\beta}$ & 0.9850 & 0.9999 \\
$\mu_{b}$ & 0.3500 & 0.2010 \\
$\mu_{d}$ & 0.3453 & 0.1987 \\
$\phi_{2}$ & -0.1595 & 0.0375 \\
$\alpha_{1}$ & 0.3903 & -0.0938 \\
$\alpha_{2}$ & -0.2510 & 0.45697 \\
$\sigma_{d^{*}}$ & 0.0286 & 0.0153 \\
$\sigma_{\hat{d}}$ & 0.0115 & 0.0113 \\
$\phi_{s}$ & 0.0599 & 0.0027 \\
\hline
\end{tabular}

model to the same shock sequence as above. It follows that the difference in the reserve levels across the two scenarios is attributed to the change in $\bar{\beta}$ alone.

Fig. 8 displays the result of the exercise. The solid line in the top panel ("All parameters change") corresponds to the case where all parameters change to the post-break values and the dashed line (" $\beta$ does not change") in the top panel to the case where only $\bar{\beta}$ remains at the pre-break value. The (green) shaded area between the two lines therefore captures the contribution of the change in $\bar{\beta}$ in the post-break reserve dynamics. The bottom panel illustrates the same shaded area in terms of reserve gaps. At the end of 20 quarters, the change in $\bar{\beta}$ accounts for approximately $24 \%$ of the total postbreak increase in international reserves, which is a quantitatively significant proportion. This is the case even though the parametrization and the shock sequence above stack the model against this finding by design. This serves as additional evidence in favor of our finding that the change in $\bar{\beta}$ (and the associated rise in concern for model misspecification) played an important quantitative role in Korea's international reserve accumulation following the Asian Financial crisis.

\section{Robust control under robust learning}

In the previous section, it was assumed that the two income factors $d^{*}$ and $\hat{d}$ of the income process (5) are observable. This allowed the social planner to formulate the optimal robust policy in terms of these variables. In reality, however, no economic agent can directly observe them. In this section, we relax this assumption by taking the income factors to be
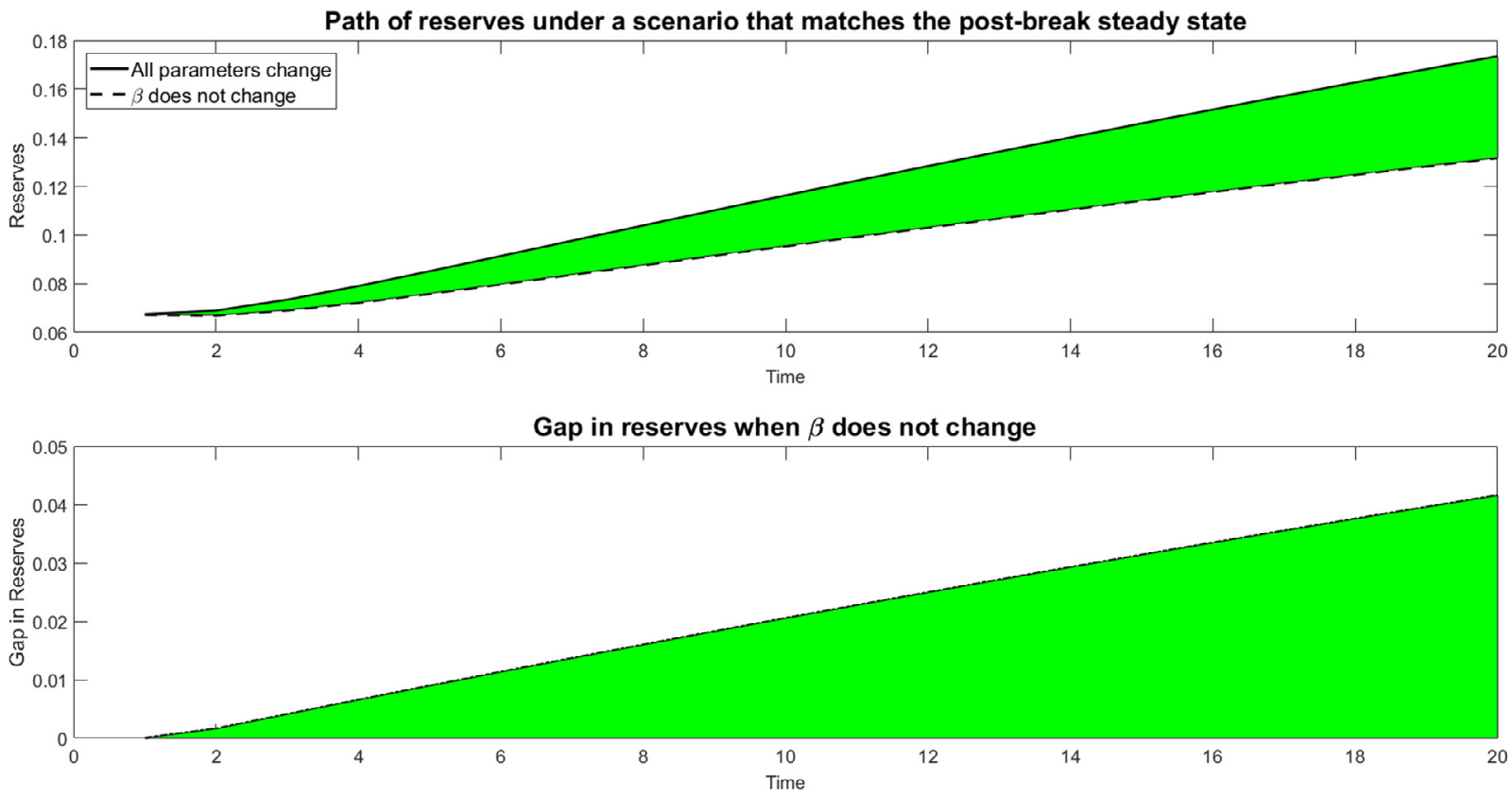

Fig. 8. Quantitative contribution of $\bar{\beta}$ under alternative calibrations. "All parameters change" in the top panel refers to the post-break estimates in Table 4 and " $\beta$ does not change" in the top panel to the scenario where only $\bar{\beta}$ remains at the pre-break estimate in Table 4 . The post-break model is subject to a shock sequence that increases the reserve-to-GDP ratio from the pre-break steady state value to the post-break steady state value in 20 quarters. The (green) shaded area between the two lines therefore captures the contribution of the change in $\bar{\beta}$ in the post-break reserve dynamics. The bottom panel illustrates the same shaded area in terms of reserve gaps. (For interpretation of the references to colour in this figure legend, the reader is referred to the web version of this article.) 
unobservable. It will be shown that learning about these variables introduces a powerful additional amplification mechanism through which shocks to the economy impinge on the dynamics of the international reserve accumulation. We will compare the results in this section to the ones under other well-known setups in the literature (including the ones in Section 3.2).

How does the social planner cope with the information gap? Here, we assume that she does so by engaging in a signal extraction exercise using a set of observables available to her (via Bayesian learning). In this regard, our approach is similar to Hur and Kondo (2016). However, we also allow the social planner to fear misspecification of her prior distribution over the unobservables. To guard against this, she applies robust control techniques to the prior distribution. In particular, she adjusts for risk about the hidden state in a way different from the usual Bayesian averaging approach. Specifically, she applies the $T^{2}$ operator to her optimal control problem, following Hansen and Sargent (2008b), Hansen et al. (2010), and Hansen and Sargent (2010). In addition to this, the social planner solves the usual robust control problem associated with the shock process of the transition law in (9) (which was discussed in Section 2.2) conditional on the hidden state. Following the convention, this procedure of making cautious evaluation due to the possibility of model misspecification is referred to as $T^{1}$ operator.

We first discuss how the robust control operators above enter a generic optimal control problem. Let $z$ denote a vector of unobservables, $x$ a vector of observables, $u$ a vector of control variables, and $\pi$ the probability density for $z$. A dynamic programming problem under distorted learning can be represented by the Bellman equation

$$
W(x, q)=\max _{u} T^{2}\left[U(u, x, z)+T^{1}\left[\beta W^{*}\left(x^{*}, \pi^{*}\right) \mid \theta_{1}\right](u, x, z, \pi) \mid \theta_{2}\right](u, x, \pi),
$$

where $U$ is an instantaneous utility function, $W$ is a value function of the problem, and the superscript * denotes tomorrow's variable. The parameter $\theta_{1}$ is the uncertainty parameter of $T^{1}$ operator (same as the $\theta$ parameter used in the previous sections) and $\theta_{2}$ is the uncertainty parameter of $T^{2}$ operator. As before, these parameters are negatively related to sizes of misspecification sets. ${ }^{32}$ Whereas $T^{1}$ operator is concerned with the impact of forward-looking distortions (as they are associated with a vector of tomorrow's shocks), $T^{2}$ operator explores the backward-looking distortions related to predicting the current hidden state given current and past information (Hansen et al., 2010; Hansen and Sargent, 2010). As discussed in Hansen et al. (2010) and Hansen and Sargent (2010), they also have well-defined risk-sensitivity operator interpretations.

In what follows, we formulate and solve the robust control problem in (19) in the context of the model in Section 2. We compare the resulting dynamics in this case to the ones under (a) robust control without learning (which was studied in Section 2) and (b) robust control with learning in which the social planner fully trusts the specification of her learning process $\left(\theta_{2}=\infty\right.$ in (19)).

\subsection{Setup}

We start by rewriting the income-generating process (5) as

$$
\begin{aligned}
& d_{t+1}=\tilde{d}_{t+1}+\phi_{s} s_{t+1}, \\
& \tilde{d}_{t+1}=\mu_{d}+d_{t+1}^{*}+\hat{d}_{t+1},
\end{aligned}
$$

and assume that $d, \tilde{d}$, and $s$ are observable. Eq. (20) implies that $\tilde{d}$ is a sufficient signal for the unobservables $d^{*}$ and $\hat{d}$ which continue to follow (6) and (7). ${ }^{33}$ Let $z_{t}=\left[d_{t}^{*}, \hat{d}_{t}, d_{t-1}^{*}, \hat{d}_{t-1}\right]^{\prime}$ denote a vector of unobservables, $x_{t}=\left[1, s_{t}, \tilde{d}_{t}\right]^{\prime}$ a vector of observables, $l_{t}=\tilde{d}_{t}$ a signal for the unobservables, and $y_{t}=\left[x_{t}^{\prime}, z_{t}^{\prime}\right]^{\prime}$. As before, $u_{t}=\mu_{b}-c_{t}$ is a control variable and $\varepsilon_{t}=$ $\left[\varepsilon_{t}^{d^{*}}, \varepsilon_{t}^{\hat{d}}\right]^{\prime}$ is a vector of shocks which is distributed according to $N(0, I)$. Using the notations of Hansen et al. (2010) and Hansen and Sargent (2010), the transition law for the unobservables is written as

$$
z_{t+1}=A_{21} x_{t}+A_{22} z_{t}+B_{2} u_{t}+C_{2} \varepsilon_{t+1}
$$

and the transition law for the sigal and the observables are

$$
\begin{aligned}
& l_{t+1}=D_{1} x_{t}+D_{2} z_{t}+H u_{t}+G \varepsilon_{t+1}, \\
& x_{t+1}=A_{11} x_{t}+A_{12} z_{t}+B_{1} u_{t}+C_{1} \varepsilon_{t+1},
\end{aligned}
$$

where the capital letters are conformable coefficient matrices. Appendix E provides their definitions.

Following Hansen et al. (2010) and Hansen and Sargent (2010), the application of the standard Kalman filter formula to Eqs. (21) and (23) yields

$$
\check{l}_{t+1}=D_{1} x_{t}+D_{2} \check{z}_{t}+H u_{t}
$$

\footnotetext{
32 Hansen et al. (2010) and Hansen and Sargent (2010) refer to this formulation of the dynamic programming problem as Game II in which both the maximizing and the minimizing player cannot observe $z$.

${ }^{33}$ Hansen et al. (2002) consider a closely related setup in which $\tilde{d}$ serves as a signal of the underlying hidden components.
} 


$$
\begin{aligned}
& \check{z}_{t+1}=A_{21} x_{t}+A_{22} \check{z}_{t}+B_{2} u_{t}+K_{2}\left(\triangle_{t}\right)\left(l_{t+1}-\check{l}_{t+1}\right), \\
& \triangle_{t+1}=A_{22} \triangle_{t} A_{22}^{\prime}+C_{2} C_{2}^{\prime}-K_{2}\left(\triangle_{t}\right)\left(A_{22} \triangle_{t} D_{2}^{\prime}+C_{2} G^{\prime}\right)^{\prime}, \\
& K_{2}\left(\triangle_{t}\right)=\left(A_{22} \triangle_{t} D_{2}^{\prime}+C_{2} G^{\prime}\right)\left(D_{2} \triangle_{t} D_{2}^{\prime}+G G^{\prime}\right)^{-1} .
\end{aligned}
$$

Here, $\check{z}_{t+1}=E\left[z_{t+1} \mid l^{t+1}\right]$ and $\check{l}_{t+1}=E\left[l_{t+1} \mid l^{t}\right]$ where $l^{t}$ denotes history of the signal $l$ up to time $t$, and $\Delta_{t}=E\left[z_{t}-\check{z}_{t}\right]\left[z_{t}-\check{z}_{t}\right]^{\prime}$. It is assumed that $z_{t} \sim N\left(\check{z}_{t}, \Delta_{t}\right)$ so that the recursion which consists of equations from (24) to (27) is sufficient for updating the probability distribution of the unobservables $z .^{34}$ Substituting (27) and (24) into (25) and stacking it together with (23) gives the transition law under learning:

$$
\left[\begin{array}{c}
x_{t+1} \\
\check{z}_{t+1}
\end{array}\right]=\left[\begin{array}{cc}
A_{11} & A_{12} \\
A_{21} & A_{22}
\end{array}\right]\left[\begin{array}{c}
x_{t} \\
\check{z}_{t}
\end{array}\right]+\left[\begin{array}{c}
B_{1} \\
B_{2}
\end{array}\right] u_{t}+\left[\begin{array}{c}
A_{12} \\
K_{2}\left(\triangle_{t}\right) D_{2}
\end{array}\right]\left(z_{t}-\check{z}_{t}\right)+\left[\begin{array}{c}
C_{1} \\
K_{2}\left(\triangle_{t}\right) G
\end{array}\right] \varepsilon_{t+1}
$$

where $K_{2}\left(\Delta_{t}\right)$ evolves according to (26) and (27). Eq. (28) indicates that now there are two sources of shocks to the economy: $\varepsilon$ and $z-\check{z}$. The former is a fundamental shock to the economy (as it is part of the income process) and the latter is an expectation error from filtering the unobservables.

\subsection{Robust learning}

We now set up the robust control problem in which the social planner is concerned about possible misspecifications of her learning process. Because the certainty equivalence principle applies in a modified sense to the current setting (see Hansen and Sargent, 2008a, we solve the deterministic version of the problem to derive the optimal policy function.

Let $w_{t}$ be the mean of $z_{t}-\check{z}_{t}$ and $v_{t}$ the mean of $\varepsilon_{t+1}$, both conditional on $\left(x_{t}, \check{z}_{t}\right)$. Due to the presence of misspecification doubts, they are different from zero here. Then, the deterministic version of the transition law (28) becomes

$$
\left[\begin{array}{c}
x_{t+1} \\
\check{z}_{t+1}
\end{array}\right]=\left[\begin{array}{ll}
A_{11} & A_{12} \\
A_{21} & A_{22}
\end{array}\right]\left[\begin{array}{l}
x_{t} \\
\check{z}_{t}
\end{array}\right]+\left[\begin{array}{c}
B_{1} \\
B_{2}
\end{array}\right] u_{t}+\left[\begin{array}{c}
A_{12} \\
K_{2}\left(\triangle_{t}\right) D_{2}
\end{array}\right] w_{t}+\left[\begin{array}{c}
C_{1} \\
K_{2}\left(\triangle_{t}\right) G
\end{array}\right] v_{t}
$$

Let $\tilde{y}_{t}=\left[x_{t}^{\prime}, \check{z}_{t}^{\prime}\right]^{\prime}, \tilde{a}_{t}=\left[u_{t}^{\prime}, w_{t}^{\prime}, v_{t}^{\prime}\right]^{\prime}$. Then, the transition law under robust learning (29) can be written as

$$
\tilde{y}_{t+1}=\tilde{A} \tilde{y}_{t}+\tilde{B}\left(\triangle_{t}\right) \tilde{a}_{t},
$$

where $\tilde{A}$ and $\tilde{B}\left(\Delta_{t}\right)$ are conformable coefficient matrices. In line with (30), we write the periodic objective function in (11) augmented by the two robust control operators, which are indexed by $\theta_{1}$ and $\theta_{2}$ respectively, as a function of $\tilde{a}_{t}$ and $\tilde{y}_{t}$. This objective function is

$$
\max _{\left\{u_{t}\right\}} \min _{\left\{w_{t}, v_{t}\right\}}-\frac{1}{2} \sum_{t=0}^{\infty} \beta^{t}\left[\tilde{a}_{t}^{\prime}, \tilde{y}_{t}^{\prime}\right] \Pi\left(\triangle_{t}\right)\left[\begin{array}{l}
\tilde{a}_{t} \\
\tilde{y}_{t}
\end{array}\right],
$$

where $\Pi\left(\Delta_{t}\right)$ is an augmented matrix. Appendix F defines the matrices $\tilde{A}, \tilde{B}\left(\Delta_{t}\right)$, and $\Pi\left(\Delta_{t}\right)$.

The robust policy function under distorted learning is obtained by solving (31) subject to (30). To make this problem more tractable, we work with the steady-state Kalman gain in what follows. ${ }^{35}$ This allows the problem in (31) to be solved as a standard linear-quadratic dynamic programming problem ${ }^{36}$ whose solution is characterized by the Riccati equation

$$
\Omega=\Pi_{22}+\beta \tilde{A}^{\prime} \Omega \tilde{A}-\left[\Pi_{12}+\beta \tilde{B}^{\prime} \Omega \tilde{A}\right]^{\prime}\left[\Pi_{11}+\beta \tilde{B}^{\prime} \Omega \tilde{B}\right]^{-1}\left[\Pi_{12}+\beta \tilde{B}^{\prime} \Omega \tilde{A}\right],
$$

and the robust optimal policy is given by

$$
\tilde{a}=-\tilde{F} \tilde{y}
$$

where

$$
\tilde{F}=\left[\Pi_{11}+\beta \tilde{B}^{\prime} \Omega \tilde{B}\right]^{-1}\left[\Pi_{12}+\beta \tilde{B}^{\prime} \Omega \tilde{A}\right] .
$$

In what follows, the impulse response functions under this solution will be compared to the ones under other widely used setups to show how learning can reinforce the accumulation of the international reserves.

\footnotetext{
34 Technically speaking, this assumption implies that equations from (24) to (27) are equivalent to the Bayes rule and the Chapman-Kolmogorov equation which are used to update and forecast a distribution of hidden states. See Fernández-Villaverde, 2010.

35 This is obtained by iterating to convergence on (26) and (27). We add a measurement error to (22) to facilitate convergence. The result in this section is robust to a wide array of values for the variance of the measurement error.

36 This also allows us to separate dynamics due to the unobservables per se from dynamics due to the evolution of the Kalman gain.
} 

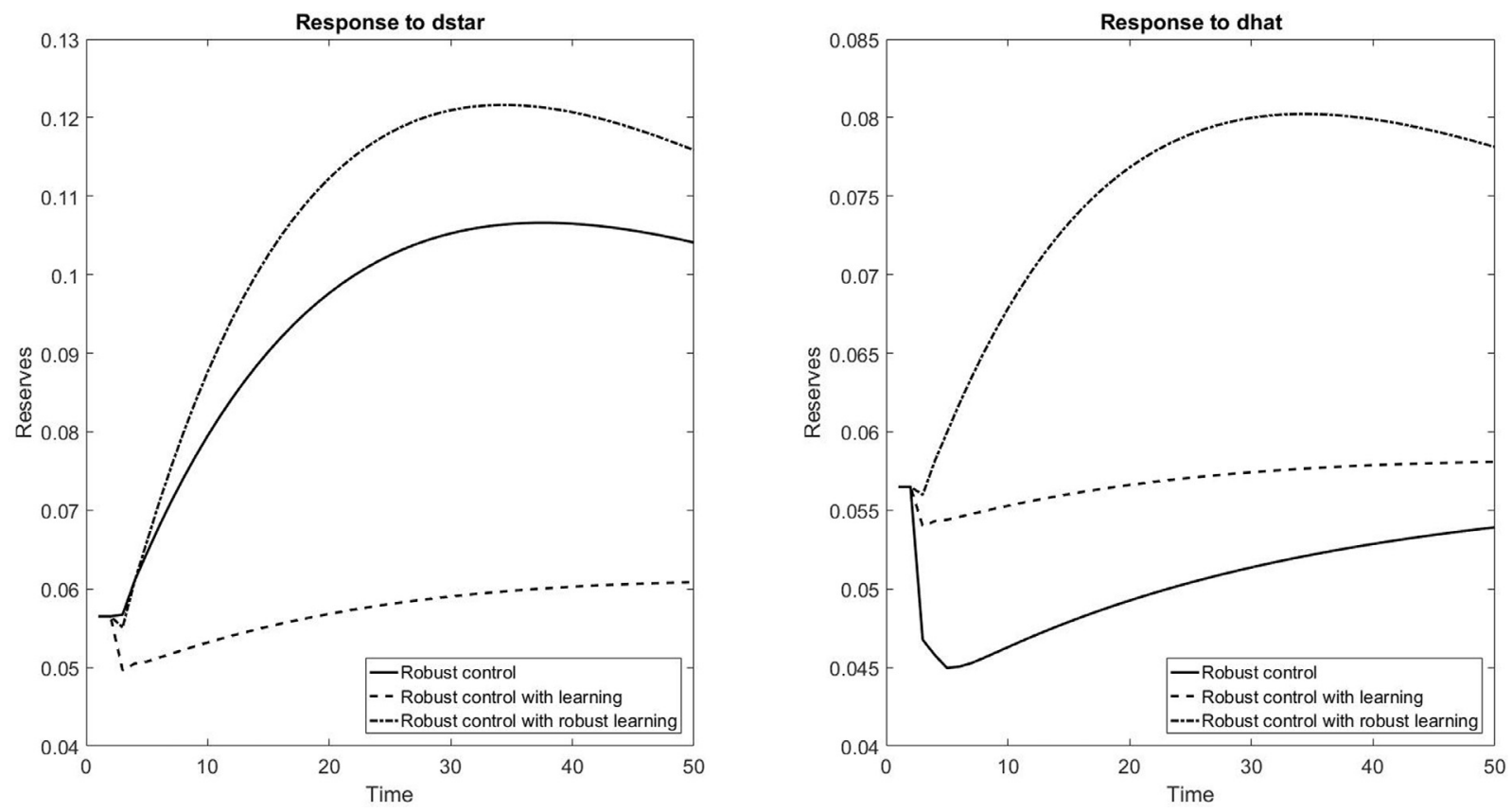

Fig. 9. Impulse response functions for fundamental shocks $\left(\theta_{2}=0.1\right)$. The figure displays the impulse response functions subject to a one standard deviation negative shock to the persistent income factor (left) and the transitory income factor (right) for various cases under consideration. "Robust control" refers to robust control without learning, "Robust control with learning" to robust control in which the specification of learning process is fully trusted, and "Robust control with robust learning" to robust control in which learning process is distorted by misspecification concerns.

\subsection{Dynamic responses to fundamental shocks and expectation errors}

In this section, we analyze dynamics of the international reserves in various decision environments. Our setup, which features learning, has been used in the context of macroeconomics (Cogley et al., 2008; 2007; Ellison and Sargent, 2012; Hansen et al., 2002) and finance (Hansen and Sargent, 2008b). We show that this setup is also useful for thinking about why Korea's international reserves surged following the Asian Financial Crisis of 1997. In particular, we will pay attention to the effect of expectation errors related to the current (hidden) state of the economy on the international reserves as this channel does not exist in the absence of learning.

The additional setups we consider are (a) robust control without learning which we studied in Section 2 and (b) robust control with standard Bayesian learning. We use $\beta=0.9566$ and $\theta_{1}=0.3409$ from Section 3.3 which is obtained based on the Korea financial data and fix other parameters at the pre-break values in Table 3. This makes the result here directly comparable to the ones on Fig. 5 under "Only $\beta$ changes". $\theta_{2}$ is set to 0.1 which gives detection error probability of $0.1654 .{ }^{37}$ As discussed in Section 3.3, this is well within the range commonly used in the literature. The decline in the detection error probability from 0.1942 in Section 3.3 to 0.1654 here indicates that the activation of robust learning on top of robust control increases the set of model misspecifications against which the social planner seeks robustness. Hence, the social planner now operates in a more uncertain environment. The result in this section is qualitatively robust for other values of $\theta_{2}$. Appendix G provides detection error probabilities under different values of $\theta_{2}$ (See Table 6).

Fig. 9 displays the impulse response functions of the fundamental shocks for various cases under consideration. The left panel shows the impulse response functions subject to a one standard deviation negative shock to the persistent income factor and the right panel those subject to a one standard deviation negative shock to the transitory income factor. The labeling conventions are as follows: "Robust control" refers to robust control without learning (studied in Section 2), "Robust control with learning" to robust control in which the social planner copes with the unobservables by learning from the observables, fully trusting the specification of her learning process, and "Robust control with robust learning" to robust control in which the social planner is concerned about misspecifications of her learning process. The initial point of the simulation exercise is fixed at the steady state of "Robust control" for all the cases. This implies that the results under "Robust control" in Fig. 9 are identical to the results under "Only $\beta$ changes" in Fig. 5.

What do we learn from Fig. 9? First, introducing the unobservables and Bayesian learning ("Robust control with learning") can dampen (left panel) or amplify (right panel) the effect of the forward-looking distortions ("Robust control"). Why does

\footnotetext{
37 We follow the suggestion in Hansen et al. (2010) and Hansen and Sargent (2010) and use the transition law for the signal to compute the detection error probability under robust learning.
} 


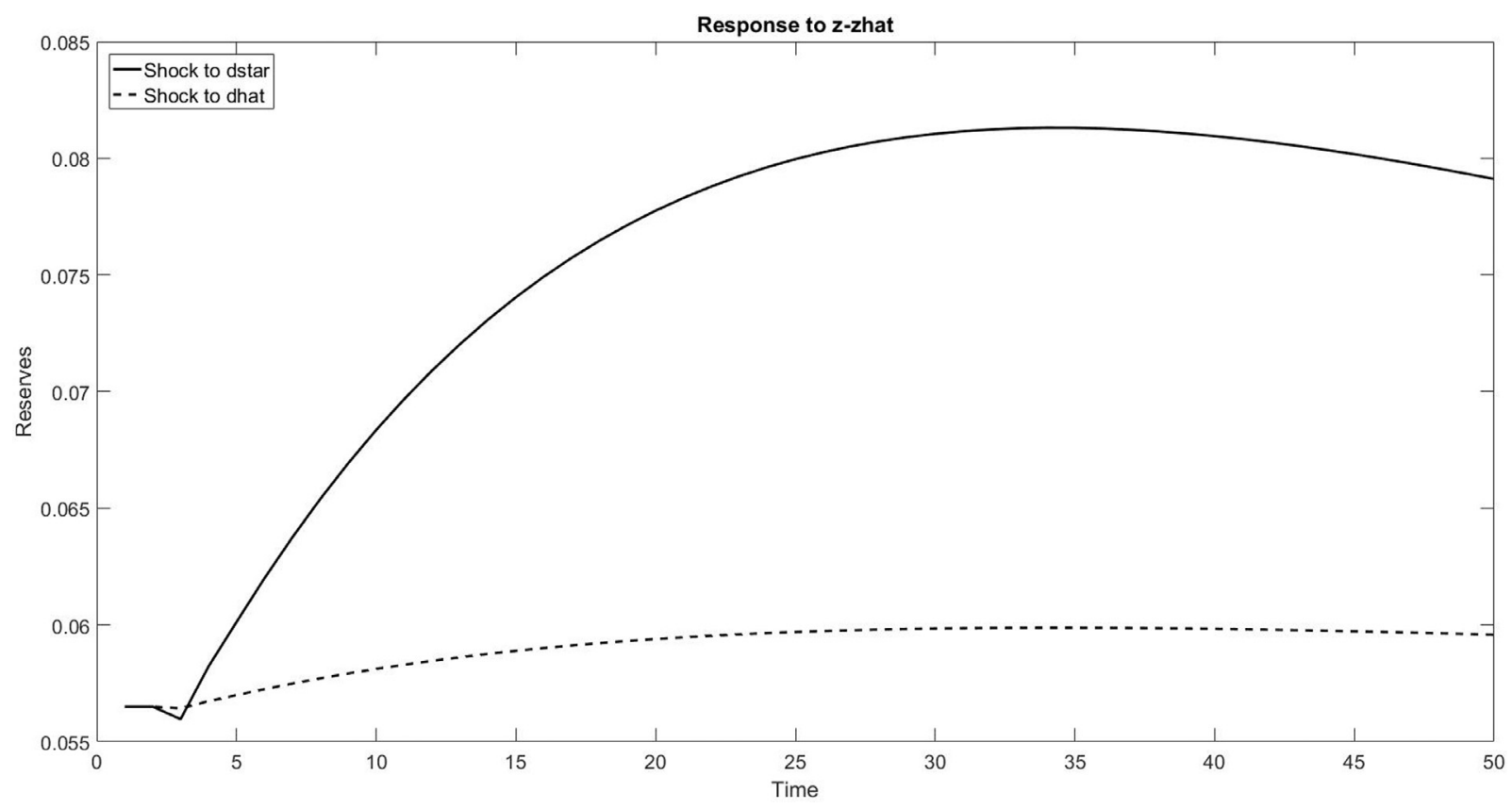

Fig. 10. Impulse response functions for expectation shocks $\left(\theta_{2}=0.1\right)$. The figure displays the impulse response functions subject to a one standard deviation shock to the expectation error about the current state of the economy. "Shock to dstar" plots the response to the shock which increases the distance between the current value of the persistent income factor and its expected value and "Shock to dhat" the response to the shock which increases the distance between the current value of the transitory income factor and its expected value.

this happen? In case of the full observability ("Robust control"), the figure shows that the social planner reacts more strongly to a one standard deviation negative shock to the income factor $d^{*}$ than $\hat{d}$. This is natural given that $d^{*}$ is both more persistent and noisier. However, when the income factors are assumed to be unobservable, the social planner only observes their sum $(\tilde{d}$ in Eq. (20)). In this case, each time a shock hits the economy, she cannot dismiss this as a shock to one income factor over the other completely. Hence, the effect of a shock to $d^{*}$ becomes dampened (being pulled down towards the effect of $\hat{d}$ ) and the effect of a shock to $\hat{d}$ gets strengthened (being pushed up towards the effect of $d^{*}$ ) relative to the case with the full observability. Second, distorting the learning process with the misspecification doubts ("Robust control with robust learning") overturns the results without these backward-looking distortions ("Robust control with learning") and leads the social planner to accumulate substantially more international reserves. This effect becomes stronger as the value of $\theta_{2}$ decreases because it increases the size of the misspecification set.

The effect of a one standard deviation negative shock to the expectation error related to the current unobservable state on the international reserve accumulation is illustrated in Fig. 10. Here, we present the results for the case with the distorted learning only as they are of utmost interest to us (in light of the discussion in the previous paragraph). "Shock to dstar" plots the response of the international reserves to the shock that increases the distance between the current value of the persistent income factor $\left(d^{*}\right)$ and its expected value and "Shock to dhat" the response to the shock which increases the distance between the current value of the transitory income factor $(\hat{d})$ and its expected value. The figure shows that their effects are strong and persistent over time. As expected, the effect under "Shock to dstar" is substantially stronger which reflects the fact that $d^{*}$ is both more persistent and noisier than $\hat{d}$.

Recall that we are building on the case from Section 3.3 in which only the discount factor $\beta$ changes ("Only $\beta$ changes" in Fig. 5) which was obtained from our empirical analysis of the structural break around the Asian Financial Crisis of 1997. As discussed above, "Robust control" in Fig. 9 in this section corresponds to this case. The simulation exercises above indicate that incorporating robust learning to this baseline robust control model can work as a powerful amplification mechanism of the economic shocks. Moreover, it introduces an additional "expectation channel" which was demonstrated to be important in the context of our model. These require only a modest decrease in the detection error probability (equivalently a modest increase in model uncertainty) relative to the case without learning.

\section{Conclusion}

In this paper, we aimed to uncover a new mechanism to understand the surge in international reserves of Asian countries following the Asian Financial Crisis of 1997. We added robust control to a simple permanent income model, estimated it with the Korean data, and found a structural break which can be interpreted as a rise in the perceived amount of model uncertainty. We demonstrated that this can lead to a persistent increase in international reserves which works through 
the heightened precautionary saving motive. Moreover, we incorporated Bayesian learning into our framework and showed that both fundamental and expectation shocks could result in sizable increases in international reserves. This indicates that learning can serve as a powerful additional amplification mechanism in our framework.

It is also interesting to note that Latin American countries, which have gone through a lot more economic crises than Asian countries have, have maintained substantially lower international reserves positions over time as Fig. 1 shows. There are a number of ways to rationalize this phenomenon. For instance, one could argue that this emerges due to lower risk/uncertainty aversion of policy makers in Latin American countries. This may be a reflection of political instability and corruption which are important determinants of international reserve accumulation (see Aizenman and Marion, 2003. Or, one could argue that having gone through many economic crises historically, Latin American countries have sharper estimates of possible downsides of crises which are not available to Asian countries due to the scarcity of such experiences. The max-min preference in our robust control problems can be understood as a way to cope with this relative inexperience about the downsides. We leave the exploration of these ideas to the future.

We argued in Section 3.3 that the mechanism behind the international reserve accumulation in the paper should be applicable to more elaborate settings. An extension of our robust control analysis to a DSGE model with private sector real and financial decisions and stochastic volatility (as in Bidder and Smith, 2012 is one possible avenue for future research. This would allow us to ask whether the Asian Financial Crisis should be understood as an one-off permanent change or an extreme but non-permanent event along a continuum of possible events. The recent work of Bhandari et al. (2017), which quantifies time-varying uncertainty using household forecasts of unemployment and inflation, is particularly relevant to this pursuit.

Finally, we plan to work on estimating learning models in Section 4 directly rather than relying on the estimates from robust control model without learning to study the effect of learning. Some progress has been made in terms of estimation methodology, for instance Calvet and Czellar (2012).

\section{Acknowledgments}

We would like to thank two anonymous referees, Cem Cakmakli, Martin Ellison, Refet Gurkaynak, Tom Holden, Ayse Kabukcuolgu, Gokce Karasoy, Burcin Kisacikoglu, Ka Fai Li, Cavit Pakel, Andrew Pua, Ju Hyun Pyun, Cagri Saglam, Byron Kwok-ping Tsang, Tommy Wu, Sevcan Yesiltas, Kamil Yilmaz, Mehmet Yorukoglu, and Tianxiao Zheng, and conference and seminar participants at ASSET 2016, CMES 2017, IDMF 2017, T2M 2017, Bilkent University, De La Salle University, Hong Kong Baptist University, and Koc University for their useful comments. All errors are our own.

\section{Appendix A. Matrices in Section 2.2}

In Section 2.2, the Eqs. (1), (2), (5), (6), and (7) are recast in matrix notation so that they are compatible with a general linear-quadratic control problem. The utility function is given by

$$
-y_{t}^{\prime} M y_{t}-u_{t}^{\prime} Q u_{t}
$$

where $Q=1$ and $M=0_{6 \times 6}$. The transition law (Eq. (8) above) takes the form

$$
y_{t+1}=A y_{t}+B u_{t}+C \varepsilon_{t+1},
$$

where

$$
\begin{aligned}
A & =\left[\begin{array}{cccccc}
1 & 0 & 0 & 0 & 0 & 0 \\
\mu_{d}-\mu_{b} & R+\phi_{s} & 1 & 0 & 1 & 0 \\
0 & 0 & \phi_{1}+\phi_{2} & -\phi_{1} \phi_{2} & 0 & 0 \\
0 & 0 & 1 & 0 & 0 & 0 \\
0 & 0 & 0 & 0 & \alpha_{1}+\alpha_{2} & -\alpha_{1} \alpha_{2} \\
0 & 0 & 0 & 0 & 1 & 0
\end{array}\right] \\
B & =\left[\begin{array}{l}
0 \\
1 \\
0 \\
0 \\
0 \\
0
\end{array}\right] \text { and } C=\left[\begin{array}{cc}
0 & 0 \\
0 & 0 \\
\sigma_{d^{*}} & 0 \\
0 & 0 \\
0 & \sigma_{\hat{d}} \\
0 & 0
\end{array}\right]
\end{aligned}
$$

\section{Appendix B. Observational equivalence theorem}

Here, we provide the observational equivalence theorem that is applicable to our setting. Hansen et al. (1999) and Hansen and Sargent (2008a) provide the observational equivalence theorems which assume $\beta R=1$. We extend the theorem to cases where $\beta R \neq 1$. The logic of the proof follows Hansen et al. (1999). The theorem is also applicable to settings with preference 
shocks or/and consumption habit formation. Intuitively, this is because the form of the Euler equation for consumption, on which our proof is built, is not altered by the inclusion of these features.

Now, the statement of the observational equivalence theorem:

The optimal policy under $\beta=\bar{\beta}$ and $\theta=\infty$ is identical to the optimal policy under $\beta=\hat{\beta}(\theta)$ and $\theta<\infty$ where $\hat{\beta}(\theta)<\bar{\beta}$ and increasing in $\theta$, holding other parameters constant.

Proof: The effective real interest is $\bar{R}=R+\phi_{s}$. The Euler equation for consumption implies a stochastic process

$$
\mu_{c t}=(\bar{\beta} \bar{R})^{-1} \mu_{c t-1}+\alpha \bar{\varepsilon}_{t}
$$

where $\mu_{s t}=c_{t}-\mu_{b}$ is the marginal utility of consumption, $\bar{\varepsilon}_{t}$ is a scalar i.i.d. process with zero mean and unit variance, and $\alpha=\sqrt{v^{\prime} v}$ where $\alpha \bar{\varepsilon}_{t}=v^{\prime} \varepsilon_{t}, \varepsilon_{t}=\left[\varepsilon_{t}^{d^{*}}, \varepsilon_{t}^{\hat{d}}\right]^{\prime}$ and $v^{\prime}=-F C$ (see Eq. (13) for $F$ and Appendix A for $C$ ).

We activate a robustness concern associated with model uncertainty by setting $\sigma<0$ where $\sigma=-\theta^{-1}$ and $\theta>0$ is a penalty parameter which governs the robustness concern. $\sigma$ is a risk-sensitivity parameter of the risk-sensitive preference that is observationally equivalent to the multiplier preference of Hansen and Sargent. The worst case model for $\mu_{c t}$ takes the form

$$
\begin{aligned}
& \mu_{c t}=(\bar{\beta} \bar{R})^{-1} \mu_{c t-1}+\alpha\left(\bar{\varepsilon}_{t}+w_{t}\right) \\
& =\left((\bar{\beta} \bar{R})^{-1}+\alpha K(\sigma, \bar{\beta}, \hat{\beta})\right) \mu_{c t-1}+\alpha \bar{\varepsilon}_{t} \\
& =\zeta(\sigma, \bar{\beta}, \hat{\beta}) \mu_{c t-1}+\alpha \bar{\varepsilon}_{t}
\end{aligned}
$$

where $w_{t}=K(\sigma, \bar{\beta}, \hat{\beta}) \mu_{c t-1}$ is the worst case distortion to the conditional mean of $\bar{\varepsilon}_{t}, \zeta(\sigma, \bar{\beta}, \hat{\beta})=(\bar{\beta} \bar{R})^{-1}+\alpha K(\sigma, \bar{\beta}, \hat{\beta})$, and $(\hat{\beta}, \sigma)$ is observationally equivalent to $(\bar{\beta}, 0)$. It follows that the optimal policy under $(\bar{\beta}, 0)$ is equivalent to that under $(\hat{\beta}, \sigma)$ if and only if

$$
(\hat{\beta} \bar{R})\left((\bar{\beta} \bar{R})^{-1}+\alpha K(\sigma, \bar{\beta}, \hat{\beta})\right)=1 .
$$

The minimizing agent's pure forecasting problem under the distorted law of motion $\mu_{c t}=(\bar{\beta} \bar{R})^{-1} \mu_{c t-1}+\alpha w_{t}$ gives the Bellman equation

$$
-P \mu_{c}^{2}=-\mu_{c}^{2}+\hat{\beta} \min _{w}\left(-\frac{1}{\sigma} w^{2}-P\left((\bar{\beta} \bar{R})^{-1} \mu_{c}+\alpha w\right)^{2}\right)
$$

where $P$ is the value matrix and $\hat{\beta}$ is the observationally equivalent discount factor. The FOC for $w$ is

$$
w=-\alpha P \mu_{c}(\bar{\beta} \bar{R})^{-1}\left(\frac{1}{\sigma}+\alpha^{2} P\right)^{-1} .
$$

Substituting this into the right-hand-side of the Bellman equation above gives,

$$
\begin{aligned}
& -\frac{1}{\sigma} w^{2}-P\left((\bar{\beta} \bar{R})^{-1} \mu_{c}+\alpha w\right)^{2} \\
& =-\frac{1}{\sigma} \alpha^{2} P^{2} \mu_{c}^{2}(\bar{\beta} \bar{R})^{-2}\left(\frac{1}{\sigma}+\alpha^{2} P\right)^{-2}-P\left((\bar{\beta} \bar{R})^{-1} \mu_{c}-\alpha^{2} P \mu_{c}(\bar{\beta} \bar{R})^{-1}\left(\frac{1}{\sigma}+\alpha^{2} P\right)^{-1}\right)^{2} \\
& =-\frac{1}{\sigma} P \mu_{c}^{2}(\bar{\beta} \bar{R})^{-2}\left(\frac{1}{\sigma}+\alpha^{2} P\right)^{-1} .
\end{aligned}
$$

Then, the minimizing agent's Bellman equation becomes

$$
P \mu_{c}^{2}=\mu_{c}^{2}+\hat{\beta} \frac{1}{\sigma} P \mu_{c}^{2}(\bar{\beta} \bar{R})^{-2}\left(\frac{1}{\sigma}+\alpha^{2} P\right)^{-1}
$$

which reduces to the quadratic equation

$$
\sigma \alpha^{2} P^{2}+\left(1-\hat{\beta}(\bar{\beta} \bar{R})^{-2}-\sigma \alpha^{2}\right) P-1=0
$$

whose positive root (as $P$ is required to be non-negative) is

$$
P(\sigma, \bar{\beta}, \hat{\beta})=\frac{\hat{\beta}(\bar{\beta} \bar{R})^{-2}+\sigma \alpha^{2}-1+\sqrt{\left(1-\hat{\beta}(\bar{\beta} \bar{R})^{-2}-\sigma \alpha^{2}\right)^{2}+4 \sigma \alpha^{2}}}{2 \sigma \alpha^{2}}>0 .
$$

Using the expression in Eq. (14) and $A=(\bar{\beta} \bar{R})^{-1}, C=\alpha, A-B F=(\bar{\beta} \bar{R})^{-1}$, and $\theta=-\sigma^{-1}$,

$$
K(\sigma, \bar{\beta}, \hat{\beta})=-\frac{\alpha \sigma P(\sigma, \bar{\beta}, \hat{\beta})(\bar{\beta} R)^{-1}}{1+\sigma \alpha^{2} P(\sigma, \bar{\beta}, \hat{\beta})}
$$


and

$$
\zeta(\sigma, \bar{\beta}, \hat{\beta})=(\bar{\beta} \bar{R})^{-1}+\alpha K(\sigma, \bar{\beta}, \hat{\beta})=\frac{(\bar{\beta} \bar{R})^{-1}}{1+\sigma \alpha^{2} P(\sigma, \bar{\beta}, \hat{\beta})} .
$$

Now, we put together

$$
\begin{aligned}
& (\hat{\beta} \bar{R}) \zeta(\sigma, \bar{\beta}, \hat{\beta})=1, \\
& \zeta(\sigma, \bar{\beta}, \hat{\beta})=\frac{(\bar{\beta} \bar{R})^{-1}}{1+\sigma \alpha^{2} P(\sigma, \bar{\beta}, \hat{\beta})}, \text { and } \\
& P(\sigma, \bar{\beta}, \hat{\beta})=\frac{\hat{\beta}(\bar{\beta} \bar{R})^{-2}+\sigma \alpha^{2}-1+\sqrt{\left(1-\hat{\beta}(\bar{\beta} \bar{R})^{-2}-\sigma \alpha^{2}\right)^{2}+4 \sigma \alpha^{2}}}{2 \sigma \alpha^{2}}
\end{aligned}
$$

to derive the pair $(\hat{\beta}, \sigma)$ that is observationally equivalent to $(\bar{\beta}, 0)$. The derivation is as follows:

$$
\begin{aligned}
& (\hat{\beta} \bar{R}) \frac{(\bar{\beta} \bar{R})^{-1}}{1+\sigma \alpha^{2} P(\sigma, \bar{\beta}, \hat{\beta})}=1 \\
& (\hat{\beta} \bar{R})(\bar{\beta} \bar{R})^{-1}=1+\sigma \alpha^{2} P(\sigma, \bar{\beta}, \hat{\beta}) \\
& \frac{\hat{\beta}}{\bar{\beta}}=1+\sigma \alpha^{2}\left[\frac{\hat{\beta}(\bar{\beta} \bar{R})^{-2}+\sigma \alpha^{2}-1+\sqrt{\left(1-\hat{\beta}(\bar{\beta} \bar{R})^{-2}-\sigma \alpha^{2}\right)^{2}+4 \sigma \alpha^{2}}}{2 \sigma \alpha^{2}}\right] \\
& 4\left(\frac{\hat{\beta}}{\bar{\beta}}-1\right)^{2}+4\left(\frac{\hat{\beta}}{\bar{\beta}}-1\right)\left(1-\hat{\beta}(\bar{\beta} \bar{R})^{-2}-\sigma \alpha^{2}\right)+\left(1-\hat{\beta}(\bar{\beta} \bar{R})^{-2}-\sigma \alpha^{2}\right)^{2} \\
& =\left(1-\hat{\beta}(\bar{\beta} \bar{R})^{-2}-\sigma \alpha^{2}\right)^{2}+4 \sigma \alpha^{2} \\
& \left(\frac{\hat{\beta}}{\bar{\beta}}-1\right)^{2}+\left(\frac{\hat{\beta}}{\bar{\beta}}-1\right)\left(1-\hat{\beta}(\bar{\beta} \bar{R})^{-2}-\sigma \alpha^{2}\right)=\sigma \alpha^{2} \\
& \left(\frac{\hat{\beta}}{\bar{\beta}}-1\right)\left(\hat{\beta}\left[\frac{1}{\bar{\beta}}-(\bar{\beta} \bar{R})^{-2}\right]-\sigma \alpha^{2}\right)=\sigma \alpha^{2} \\
& \frac{\hat{\beta}}{\bar{\beta}}\left[\frac{1}{\bar{\beta}}-(\bar{\beta} \bar{R})^{-2}\right]=\frac{1}{\bar{\beta}}-(\bar{\beta} \bar{R})^{-2}+\frac{\sigma \alpha^{2}}{\bar{\beta}} \\
& \frac{\hat{\beta}}{\bar{\beta}}=1+\frac{\frac{\sigma \alpha^{2}}{\bar{\beta}}}{\left[\frac{1}{\bar{\beta}}-(\bar{\beta} \bar{R})^{-2}\right]} \\
& \hat{\beta}(\bar{\beta}, \sigma)=\bar{\beta}+\frac{\sigma \alpha^{2}}{\left[\frac{1}{\bar{\beta}}-(\bar{\beta} \bar{R})^{-2}\right]} . \\
& (\hat{\beta} \hat{\beta} \bar{\beta}
\end{aligned}
$$

When $\sigma=0, \hat{\beta}(\bar{\beta}, 0)=\bar{\beta}$. Because $0<\bar{\beta}<1$ and $\bar{\beta} \bar{R} \geq 1$, the denominator of the second term of our observational equivalence formula above is positive. Then, $\hat{\beta}(\bar{\beta}, \sigma)<\bar{\beta}$ for $\sigma<0$ or equivalently $\theta<\infty$. It also follows that $\hat{\beta}(\bar{\beta}, \sigma)$ is an increasing function of $\theta$ because it is an increasing function of $\sigma$.

For the special case of $\bar{\beta} \bar{R}=1$, which corresponds to Hansen et al. (1999) and Hansen and Sargent (2008a), the formula above reduces to the well-known observational equivalence formula

$$
\hat{\beta}(\bar{\beta}, \sigma)=\frac{1}{\bar{R}}+\frac{\sigma \alpha^{2}}{\bar{R}-1} .
$$

The formula above can be inverted to obtain $\theta=-\sigma^{-1}$ for given values of $\bar{\beta}$ and $\hat{\beta}$. In Section 3.3, we use this inverse formula to back out a decrease in $\theta$ that is observationally equivalent to an increase in $\bar{\beta}$ following the Asian Financial Crisis. 


\section{Appendix C. Derivation of Eqs. (17) and (18)}

In the steady state, Eq. (5) becomes

$$
\bar{d}=\mu_{d}+\phi_{s} \bar{s}
$$

and Eq. (2)

$$
(1-R) \bar{s}=\bar{d}-\bar{c}
$$

Because $\bar{c}=\mu_{b}$ in the steady state, substituting Eq. (2) into (5) gives

$$
\begin{aligned}
& (1-R) \bar{s}=\left(\mu_{d}+\phi_{s} \bar{s}\right)-\mu_{b} \\
& \bar{s}\left(1-\left(R+\phi_{s}\right)\right)=\mu_{d}-\mu_{b} \\
& \bar{s}=\frac{\mu_{d}-\mu_{b}}{1-\left(R+\phi_{s}\right)}
\end{aligned}
$$

which is Eq. (17). It follows that the steady state income level

$$
\bar{d}=\mu_{d}+\phi_{s}\left(\frac{\mu_{d}-\mu_{b}}{1-\left(R+\phi_{s}\right)}\right)=\frac{\mu_{d}(1-R)-\phi_{s} \mu_{b}}{1-\left(R+\phi_{s}\right)} .
$$

Taking the ratio of $\bar{s}$ to $\bar{d}$,

$$
\frac{\bar{s}}{\bar{d}}=\frac{\mu_{d}-\mu_{b}}{\mu_{d}(1-R)-\phi_{s} \mu_{b}}
$$

which gives Eq. (18).

\section{Appendix D. Empirical analysis with Thai data}

Here, we rerun the empirical exercise in Section 3 using Thai data. We perform this exercise for Thailand to demonstrate that our proposed mechanism for the accumulation of international reserves works not just for Korea, but for other economies affected by the Asian Financial Crisis as well. To avoid being repetitive, we omit many details here.

Fig. 11 shows the detrended real GDP (dashed line in red) and real international reserves (solid line in blue) for Thailand (in million USD) from Q1:1993 to Q4:2015. Due to the data availability constraint, the time series are much shorter than

\section{Quarterly Detrended Real GDP and Real International Reserves (in Million USD)}

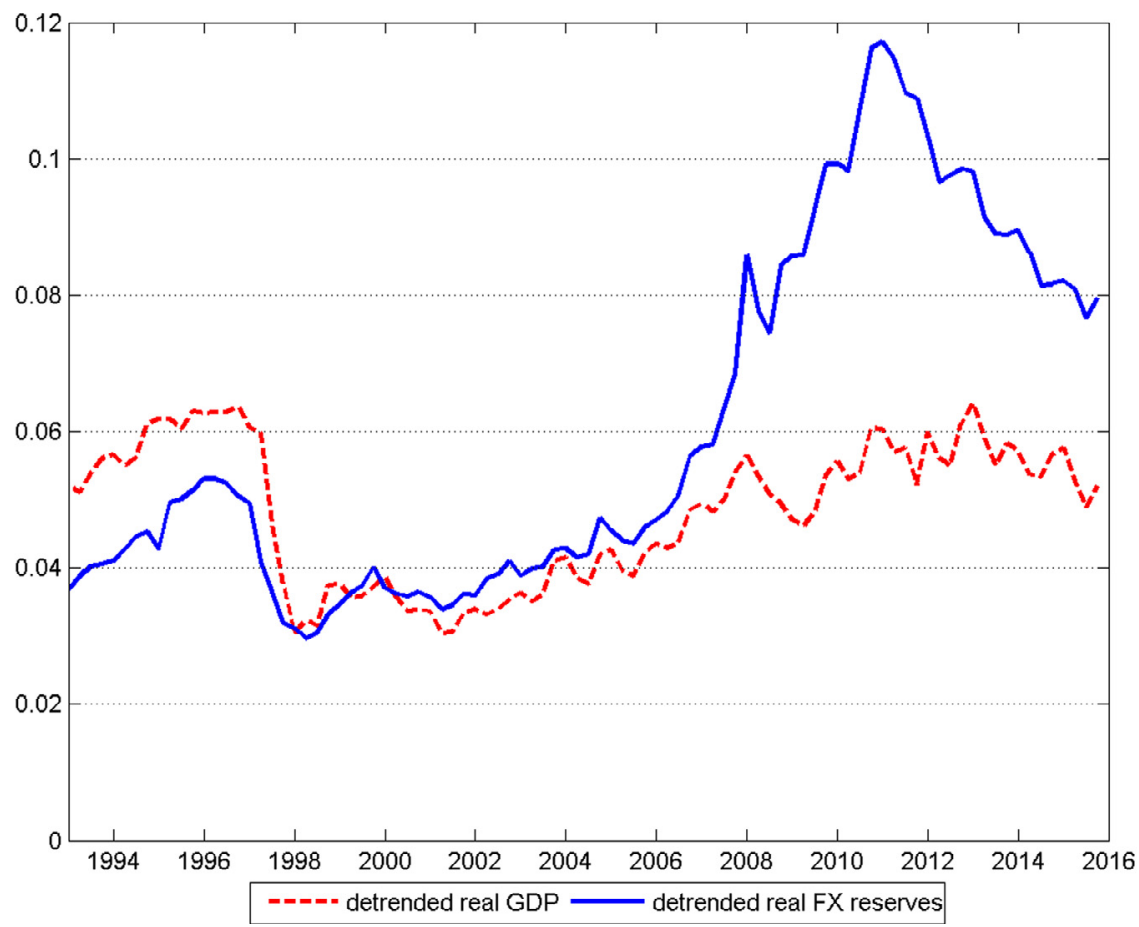

Fig. 11. Quarterly detrended real GDP and real international reserves for Thailand (Q1:1993 to Q4:2015). (For interpretation of the references to colour in this figure legend, the reader is referred to the web version of this article.) 


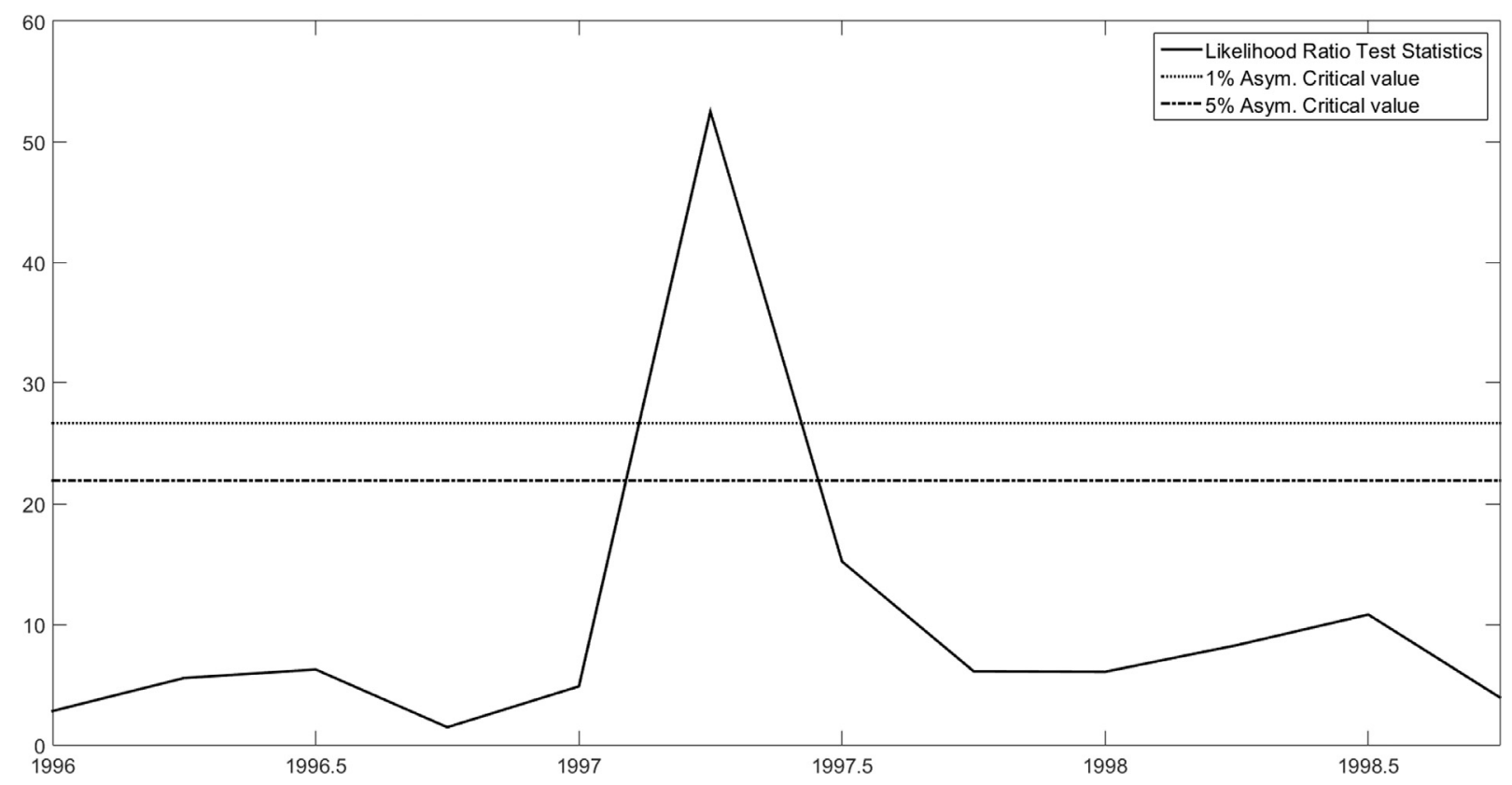

Fig. 12. $2 \times$ Likelihood ratios and Andrews supremum test for Thai data. Refer to Fig. 4 for the figure conventions.

Table 5

Whole sample and sub-sample estimates for Thailand.

\begin{tabular}{llll}
\hline Parameter & Before the break & After the break & Whole sample \\
\hline $\bar{\beta}$ & 0.9508 & 0.9606 & 0.9555 \\
$\mu_{d}$ & 0.4999 & 0.5000 & 0.5000 \\
$\phi_{1}$ & 0.9999 & 0.9996 & 0.9986 \\
$\phi_{2}$ & 0.5031 & 0.7819 & 0.5976 \\
$\alpha_{1}$ & 0.2951 & 0.4890 & 0.3033 \\
$\alpha_{2}$ & 0.2959 & 0.4891 & 0.4538 \\
$\sigma_{d^{*}}$ & 0.0021 & 0.0015 & 0.0028 \\
$\sigma_{\hat{d}}$ & 0.0022 & 0.0030 & 0.0035 \\
$\phi_{s}$ & 0.0415 & 0.0310 & 0.0376
\end{tabular}

The whole sample ranges from Q1:1993 to Q4:2015. Q2:1997 is selected as the break point based on the Andrews test. Table 1 provides explanations about the parameters.

what we have for South Korea. However, the figure reveals a clear upward trend in the reserve accumulation following the Asian Financial Crisis. As in Section 3.2, we test this hypothesis formally.

Fig. 12 plots the Andrews test statistics. Despite the shorter sample period, a structural break is found in Q2:1997. This matches well with the speculative attacks against Thai Baht in May 1997 which is usually taken to be the starting point of the Asian Financial Crisis.

Table 5 provides the estimates for the whole sample as well as the sub-samples. In line with what we found using the Korea data, $\bar{\beta}$ increases significantly after the break. Again, this can be interpreted as an increase in the perceived amount of model uncertainty due to the observational equivalence result. We take the result in this section as a robustness test for the result in Section 3.

\section{Appendix E. Matrices in Section 4.1}

Here, we provide details about the Eqs. (21)-(23) in Section 4.1.

The transition law for the unobservables has a compact representation (Eq. (21) above)

$$
z_{t+1}=A_{21} x_{t}+A_{22} z_{t}+B_{2} u_{t}+C_{2} \varepsilon_{t+1}
$$

where

$$
A_{21}=0_{4 \times 3}, A_{22}=\left[\begin{array}{cccc}
\phi_{1}+\phi_{2} & 0 & -\phi_{1} \phi_{2} & 0 \\
0 & \alpha_{1}+\alpha_{2} & 0 & -\alpha_{1} \alpha_{2} \\
1 & 0 & 0 & 0 \\
0 & 1 & 0 & 0
\end{array}\right], B_{2}=0_{4 \times 1} \text {, and } C_{2}=\left[\begin{array}{cc}
\sigma_{d^{*}} & 0 \\
0 & \sigma_{\hat{d}} \\
0 & 0 \\
0 & 0
\end{array}\right] \text {. }
$$

This is simply the restatement of Eqs. (6) and (7) in a Vector Autoregression (VAR) form. 
The transition law for the signal (Eq. (22) above) is

$$
l_{t+1}=D_{1} x_{t}+D_{2} z_{t}+H u_{t}+G \varepsilon_{t+1},
$$

where

$$
D_{1}=\left[\mu_{d}, 0,0\right], D_{2}=\left[\begin{array}{llll}
\phi_{1}+\phi_{2} & \alpha_{1}+\alpha_{2} & -\phi_{1} \phi_{2} & -\alpha_{1} \alpha_{2}
\end{array}\right], H=0, \text { and } G=\left[\begin{array}{ll}
\sigma_{d^{*}} & \sigma_{\hat{d}}
\end{array}\right] .
$$

Substituting this into the transition law for the observables

$$
x_{t+1}=\Pi_{l} l_{t+1}+\Pi_{x} x_{t}+\Pi_{u} u_{t},
$$

where

$$
\Pi_{l}=\left[\begin{array}{l}
0 \\
0 \\
1
\end{array}\right], \Pi_{x}=\left[\begin{array}{ccc}
1 & 0 & 0 \\
-\mu_{b} & R+\phi_{s} & 1 \\
0 & 0 & 0
\end{array}\right] \text {, and } \Pi_{u}=\left[\begin{array}{l}
0 \\
1 \\
0
\end{array}\right]
$$

gives the reduced-form transition law for the observables (Eq. (23) above)

$$
x_{t+1}=A_{11} x_{t}+A_{12} z_{t}+B_{1} u_{t}+C_{1} \varepsilon_{t+1},
$$

where $A_{11}=\Pi_{l} D_{1}+\Pi_{x}, A_{12}=\Pi_{l} D_{2}, B_{1}=\Pi_{l} H+\Pi_{u}$, and $C_{1}=\Pi_{l} G$.

\section{Appendix F. Matrices in Section 4.2}

The matrices for the Eqs. (30) and (31) in Section 4.2 are presented here.

The transition law under robust learning (Eq. (30) above) is

$$
\tilde{y}_{t+1}=\tilde{A} \tilde{y}_{t}+\tilde{B}\left(\triangle_{t}\right) \tilde{a}_{t},
$$

where

$$
\tilde{A}=\left[\begin{array}{ll}
A_{11} & A_{12} \\
A_{21} & A_{22}
\end{array}\right] \text { and } \tilde{B}\left(\triangle_{t}\right)=\left[\begin{array}{ccc}
B_{1} & A_{12} & C_{1} \\
B_{2} & K_{2}\left(\triangle_{t}\right) D_{2} & K_{2}\left(\triangle_{t}\right) G
\end{array}\right] \text {. }
$$

The objective function (Eq. (31) above) is

$$
\begin{aligned}
& \max _{\left\{u_{t}\right\}} \min _{\left\{w_{t}, v_{t}\right\}} \sum_{t=0}^{\infty} \beta^{t} r\left(\tilde{a}_{t}, \tilde{y}_{t}\right) \text {, where } r\left(\tilde{a}_{t}, \tilde{y}_{t}\right)=-\frac{1}{2}\left[\tilde{a}_{t}^{\prime}, \tilde{y}_{t}^{\prime}\right] \Pi\left(\triangle_{t}\right)\left[\begin{array}{l}
\tilde{a}_{t} \\
\tilde{y}_{t}
\end{array}\right], \\
& \Pi(\Delta)=\left[\begin{array}{ll}
\Pi_{11} & \Pi_{12} \\
\Pi_{21} & \Pi_{22}
\end{array}\right] \text { with } \Pi_{11}=\left[\begin{array}{ccc}
Q & P_{2} & 0_{1 \times 2} \\
P_{2}^{\prime} & M_{22}-\theta_{2} \Delta^{-1} & 0_{4 \times 2} \\
0_{2 \times 1} & 0_{2 \times 4} & -\theta_{1} I_{2 \times 2}
\end{array}\right], \\
& \Pi_{12}=\Pi_{21}^{\prime}=\left[\begin{array}{cc}
P_{1} & P_{2} \\
M_{21} & M_{22} \\
0_{2 \times 3} & 0_{2 \times 4}
\end{array}\right] \text { as M's are symmetric, } \Pi_{22}=\left[\begin{array}{cc}
R_{11} & R_{12} \\
R_{21} & R_{22}
\end{array}\right] \text {, } \\
& Q=1, P_{1}=0_{1 \times 3}, P_{2}=0_{1 \times 4}, M_{11}=0_{3 \times 3}, M_{12}=0_{3 \times 4}, M_{21}=0_{4 \times 3} \text {, and } M_{22}=0_{4 \times 4} \text {. }
\end{aligned}
$$

\section{Appendix G. Robust learning parameter $\theta_{2}$ and detection error probability $p$}

Table 6

Robust learning parameter $\theta_{2}$ and detection error probability $p$.

\begin{tabular}{ll}
\hline$\theta_{2}$ & $p$ \\
\hline 0.08 & 0.1419 \\
0.1 & 0.1654 \\
0.12 & 0.1784 \\
\hline
\end{tabular}

We use $\beta=0.9566$ and $\theta_{1}=0.3409$ from Section 3.3 which are obtained based on Korea financial data and fix other parameters at the pre-break values in Table 3. 


\section{References}

Aizenman, J., Lee, J., 2007. International reserves: precautionary versus mercantilist views, theory and evidence. Open Econ. Rev. 18 (2), 191-214. Springer. Aizenman, J., Lee, J., 2008. Financial versus monetary mercantilism: long-run view of large international reserves hoarding. World Econ. 31 (5), 593-611. Wiley Blackwell, 05.

Aizenman, J., Lee, Y., Rhee, Y., 2007. International reserves management and capital mobility in a volatile world: policy considerations and a case study of korea. J. Japanese Int. Econ. 21 (1), 1-15. Elsevier.

Aizenman, J., Marion, N., 2003. The high demand for international reserves in the far east: what is going on? J. Japanese Int. Econ. 17 (3), 370-400. Elsevier. Albuquerque, L., Eichenbaum, M., Luo, V.X., Rebelo, S., 2016. Valuation risk and asset pricing. J. Finance 71 (6), $2861-2904$.

Anderson, E.W., Hansen, L.P., Sargent, T.J., 2003. A quartet of semigroups for model specification, robustness, prices of risk, and model detection. J. Eur. Econ. Assoc. 1 (1), 68-123. MIT Press.

Anderson, E.W., Hansen, L.P., Sargent, T.J., 2012. Small noise methods for risk-sensitive/robust economies. J. Econ. Dyn. Control 36 (4), 468-500. Elsevier.

Andrews, D.W.K., 1993. Tests for parameter instability and structural change with unknown change point. Econom. Econom. Soc. 61 (4), 821-856. July.

Andrews, D.W.K., 2003. Tests for parameter instability and structural change with unknown change point: a corrigendum. Econom. Econom. Soc. 71 (1), 395-397. January.

Bacchetta, P., Benhima, K., Kalantzis, Y., 2013. Capital controls with international reserve accumulation: can this be optimal? Am. Econ. J. Macroecon. Am. Econ. Assoc. 5 (3), 229-262.

Barillas, F., Hansen, L.P., Sargent, T.J., 2009. Doubts or variability? J. Econ. Theory 144 (6), 2388-2418. Elsevier.

Barro, R.J., 2006. Rare disasters and asset markets in the twentieth century. Q. J. Econ. 121 (3), 823-866. Oxford University Press.

Beck, R., Weber, S., 2011. Should larger reserve holdings be more diversified? Int. Finance 14 (3), 415-444.

Benigno, G., Fornaro, L., 2012. Reserve accumulation, growth and financial crises. Discussion Paper No 1161. Centre for Economic Performance.

Bernanke, B.S., 2005. The Global Saving Glut and the U.S. Current Account Deficit. Board of Governors of the Federal Reserve System (U.S.). Speech 77.

Bhandari, A., Borovicka, J., Ho, P., 2017. Survey Data and Subjective Beliefs in Business Cycle models. Working Paper. University of Minnesota.

Bianchi, J., Hatchondo, J.C., Martinez, L., 2016. International Reserves and Rollover Risk. Working Papers 735. Federal Reserve Bank of Minneapolis.

Bidder, R.M., Smith, M.E., 2012. Robust animal spirits. J. Monet. Econ. 59 (8), 738-750.

Bussière, M., Cheng, G., Chinn, M.D., Lisack, N., 2015. For a few dollars more: reserves and growth in times of crises. J. Int. Money Finance 52 (C), 127-145. Elsevier.

Calvet, L., Czellar, V., 2012. Efficient Estimation of Learning Models. Working Papers hal-00674226, HAL.

Calvo, G.A., Izquierdo, A., Loo-Kung, R., 2012. Optimal Holdings of International Reserves: Self-insurance Against Sudden Stop. NBER Working Papers 18219. National Bureau of Economic Research, Inc.

Choi, W.J., Taylor, A.M., 2017. Precaution Versus Mercantilism: Reserve Accumulation, Capital Controls, and the Real Exchange Rate. NBER Working Papers 23341. National Bureau of Economic Research, Inc.

Christiano, L., Eichenbaum, M., Rebelo, S., 2011. When is the government spending multiplier large? J. Polit. Econ. 119 (1), $78-121$. University of Chicago Press.

Cochrane, J.H., 2016. The Habit Habit. Hoover Institution Economics Working Papers 16105. Hoover Institution.

Cogley, T., Colacito, R., Hansen, L.P., Sargent, T.J., 2008. Robustness and u.s. monetary policy experimentation. J. Money Credit Bank. 40 (8), $1599-1623$. Blackwell Publishing.

Cogley, T., Colacito, R., Sargent, T.J., 2007. Benefits from u.s. monetary policy experimentation in the days of samuelson and solow and lucas. J. Money Credit Bank. 39 (s1), 67-99. Blackwell Publishing.

Dominguez, K.M.E., Hashimoto, Y., Ito, T., 2012. International reserves and the global financial crisis. J. Int. Econ. 88 (2), $388-406$. Elsevier.

Dooley, M.P., Folkerts-Landau, D., Garber, P., 2003. An Essay on the Revived Bretton Woods System. NBER Working Papers 9971. National Bureau of Economic Research, Inc.

Dooley, M.P., Folkerts-Landau, D., Garber, P., 2005. Savings Gluts and Interest Rates: The Missing Link to Europe. NBER Working Papers 11520. National Bureau of Economic Research, Inc.

Ellison, M., Sargent, T.J., 2012. A defense of the FOMC. Int. Econ. Rev. 53 (4), 1047-1065. Department of Economics, University of Pennsylvania and Osaka University Institute of Social and Economic Research Association.

Ellison, M., Sargent, T.J., 2015. Welfare cost of business cycles with idiosyncratic consumption risk and a preference for robustness. Am. Econ. J. Macroecon. Am. Econ. Assoc. 7 (2), 40-57.

Epstein, L.G., Zin, S.E., 1991. Substitution, risk aversion, and the temporal behavior of consumption and asset returns: An empirical analysis. J. Polit. Econ. 99 (2), 263-286. University of Chicago Press.

Fernández-Villaverde, J., 2010. The econometrics of DSGE models. SERIEs, Spanish Econ. Assoc. 1 (1), 3-49.

Fukuda, S., Kon, Y., 2010. Macroeconomic Impacts of Foreign Exchange Reserve Accumulation: Theory and International Evidence. ADBI Working Papers 197. Asian Development Bank Institute.

Gerlach, R., Wilson, P., Zurbruegg, R., 2006. Structural breaks and diversification: The impact of the 1997 asian financial crisis on the integration of asia-pacific real estate markets. J. Int. Money Finance 25 (6), 974-991. Elsevier.

Ghosh, A.R., Ostry, J.D., Tsangarides, C.G., 2017. Shifting motives: Explaining the buildup in official reserves in emerging markets since the 1980's. IMF Econ. Rev. 65 (2), 308-364. Springer.

Gilboa, I., Schmeidler, D., 1989. Maxmin expected utility with non-unique prior. J. Math. Econ. 18 (2), 141-153. Elsevier.

Giordani, P., Soderlind, P., 2004. Solution of macromodels with hansen-sargent robust policies: Some extensions. J. Econ. Dyn. Control 28 (12), $2367-2397$. Elsevier.

Hall, R.E., 1978. Stochastic implications of the life cycle-permanent income hypothesis: Theory and evidence . J. Political Econ. 86 (6), $971-981$.

Hansen, L.P., Heaton, J.C., Li, N., 2008. Consumption strikes back? measuring long-run risk. J. Polit. Econ. 116 (2), 260-302. University of Chicago Press.

Hansen, L.P., Jagannathan, R., 1991. Implications of security market data for models of dynamic economies. J. Polit. Econ. 99 (2), 225-262. University of Chicago Press.

Hansen, L.P., Mayer, R., Sargent, T.J., 2010. Robust hidden markov LQG problems. J. Econ. Dyn. Control 34 (10), 1951-1966. Elsevier.

Hansen, L.P., Sargent, T.J., 2008a. Robustness. Princeton University Press.

Hansen, L.P., Sargent, T.J., 2008b. Fragile beliefs and the price of uncertainty. Working Paper. University of Chicago.

Hansen, L.P., Sargent, T.J., 2010. Wanting robustness in macroeconomics, handbook of monetary economics. In: Friedman, B.M., Woodford, M. (Eds.), Handbook of Monetary Economics, vol. 3, pp. 1097-1157. Chapter 20, Elsevier.

Hansen, L.P., Sargent, T.J., Tallarini, T., 1999. Robust permanent income and pricing. Rev. Econ. Stud. 66 (4), 873-907. Oxford University Press.

Hansen, L. P., Sargent, T. J., Tallarini, T. D., 1997. Robust Permanent Income and Pricing. GSIA Working Papers, Carnegie Mellon University, Tepper School of Business.

Hansen, L.P., Sargent, T.J., Wang, N.E., 2002. Robust permanent income and pricing with filtering. Macroecon. Dyn. 6 (01), 40-84. Cambridge University Press.

He, D., Luk, P., 2017. A model of Chinese capital account liberalisation. Macroecon. Dyn. 21 (8), 1902-1934.

Hur, S., Kondo, I.O., 2016. A theory of rollover risk, sudden stops, and foreign reserves. J. Int. Econ. 103 (C), $44-63$. Elsevier.

Jeanne, O., 2007. International reserves in emerging market countries: too much of a good thing? In: Brookings Papers on Economic Activity, Economic Studies Program, 38(1). The Brookings Institution, pp. 1-80. 
Jeanne, O., 2013. Capital account policies and the real exchange rate. In: Giavazzi, F., West, K. (Eds.), NBER International Seminar on Macroeconomics 2012. University of Chicago Press, Chicago.

Jeanne, O., Rancière, R., 2011. The optimal level of international reserves for emerging market countries: a new formula and some applications. Econ. J. R. Econ. Soc. 121 (555), 905-930

Klibanoff, P., Marinacci, M., Mukerji, S., 2005. A smooth model of decision making under ambiguity. Econometrica 73 (6), 1849-1892. Econometric Society.

Klibanoff, P., Marinacci, M., Mukerji, S., 2009. Recursive smooth ambiguity preferences. J. Econ. Theory 144 (3), $930-976$. Elsevier.

Knight, F. H., 1921. Risk, Uncertainty, and Profit, Hart, Schaffner \& Marx; Houghton Mifflin Co.

Lee, J., Song, J., 2011. Oil and macroeconomy: the case of korea. In: Commodity Prices and Markets, East Asia Seminar on Economics, 20, pp. 263-290.

Lim, K.M., 2012. Structural fundamentals of korean corporations: this time was different. In: Global Economic Crisis. Edward Elgar Publishing.

Luo, Y., Nie, J., Young, E.R., 2012. Robustness, information- processing constraints, and the current account in small open economies. J. Int. Econ. 88 (1), 104-120. Elsevier.

Lütkepohl, H., 2009. Econometric analysis with vector autoregressive models. In: Belsley, D.A., Kontoghiorghes, E.J. (Eds.), Handbook of Computational Econometrics. John Wiley \& Sons, Ltd, Chichester, UK.

Obstfeld, M., Shambaugh, J.C., Taylor, A.M., 2010. Financial stability, the trilemma, and international reserves. Am. Econ. J. Macroecon. 2 (2), 57-94.

Park, K.Y., Kim, K.H., 2009. Explaining the equity premium in korea. J. Korean Econ. 10 (2), 151-176.

Rietz, T.A., 1988. The equity risk premium: a solution. J. Monet. Econ. 22 (1), 117-131. Elsevier.

Ruge-Murcia, F.J., 2007. Methods to estimate dynamic stochastic general equilibrium models. J. Econ. Dyn. Control 31 (8), 2599-2636. Elsevier

Wen, Y., 2011. Making Sense of China's Excessive Foreign Reserves. Working Papers, Federal Reserve Bank of St. Louis, 2011-006. 